Portland State University

PDXScholar

\title{
Effects of shift work on employee retention : an examination of job satisfaction, organizational commitment, and stress-based explanations
}

Kristin Elizabeth Charles

Portland State University

Follow this and additional works at: https://pdxscholar.library.pdx.edu/open_access_etds

Part of the Psychology Commons

Let us know how access to this document benefits you.

\section{Recommended Citation}

Charles, Kristin Elizabeth, "Effects of shift work on employee retention : an examination of job satisfaction, organizational commitment, and stress-based explanations" (2004). Dissertations and Theses. Paper 4026.

https://doi.org/10.15760/etd.5910

This Thesis is brought to you for free and open access. It has been accepted for inclusion in Dissertations and Theses by an authorized administrator of PDXScholar. Please contact us if we can make this document more accessible: pdxscholar@pdx.edu. 


\section{THESIS APPROVAL}

The abstract and thesis of Kristin Elizabeth Charles for the Master of Science in

Psychology were presented November 1, 2004, and accepted by the thesis committee and the department.

COMMITTEE APPROVALS:

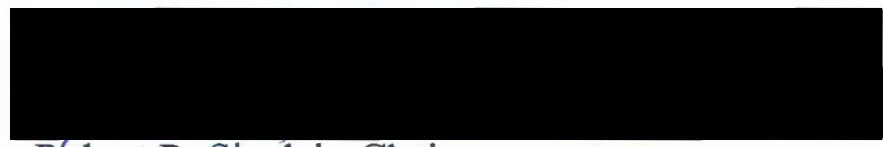

R'obert R. Sinclair, Chair

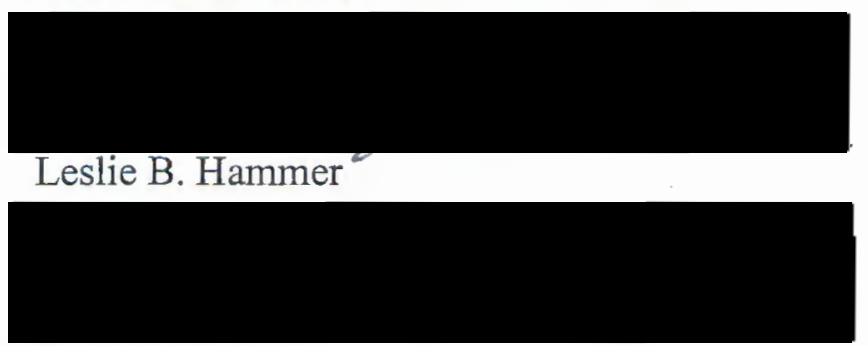

Todd E. Bodner

DEPARTMENT APPROVAL:

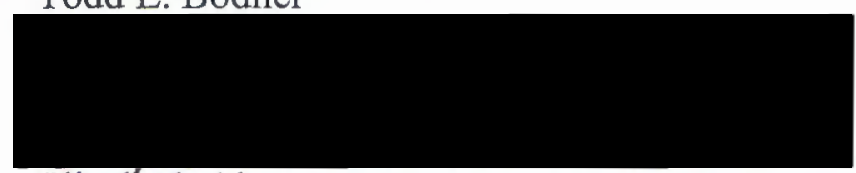

Elizajoth Almer

Representative of the Office of Graduate Studies

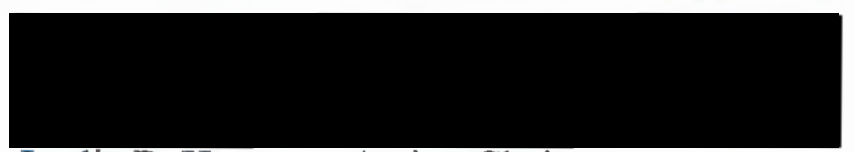

Leslie B. Hammer, Acting Chair

Department of Psychology 


\section{ABSTRACT}

An abstract of the thesis of Kristin Elizabeth Charles for the Master of Science in Psychology presented November 1, 2004.

Title: Effects of shift work on employee retention: An examination of job satisfaction, organizational commitment, and stress-based explanations

Shift work is becoming increasingly prevalent in our society, with $17 \%$ of the full-time work force and $36 \%$ of the part-time work force working non-standard shifts (Beers, 2000). The goal of this study was to explore the relationships between several shift work variables and retention of employees working in a retail organization that is open 24-hours a day. Results indicated no significant differences between workers in fixed versus mixed shift schedules on job satisfaction or role stress. Contrary to my hypothesis, mixed shift workers reported higher levels of commitment and remained with the organization longer than fixed shift workers. As predicted, night shift workers reported lower levels of job satisfaction and organizational commitment than evening workers. However contrary to predictions, there were no significant differences between morning and night shift workers. Supervisor support did not moderate the relationship between shift work and commitment, satisfaction, or role stress. However is was a significant moderator of the relationship between day versus evening shift and role stress, with individuals working evening shifts and perceiving high levels of supervisor support remaining with the organization the longest. 
Findings from this study indicate that mixed shift work and evening work may result in more positive organizational outcomes than fixed shift work or day or night work. Results of this study emphasize the need for more research concerning the relationships between shift work and organizational variables. 
EFFECTS OF SHIFT WORK ON EMPLOYEE RETENTION:

AN EXAMINATION OF JOB SATISFACTION, ORGANIZATIONAL COMMITMENT, AND STRESS-BASED EXPLANATIONS

by

KRISTIN ELIZABETH CHARLES

A thesis submitted in partial fulfillment of the requirements for the degree of

MASTER OF SCIENCE

in PSYCHOLOGY

Portland State University

2004 


\section{Acknowledgements}

I would like to acknowledge and thank Drs. Leslie Hammer, Todd Bodner and Elizabeth Almer for being a part of my thesis committee. I would especially like to express my appreciation to Dr. Robert Sinclair for the immense support and encouragement throughout this project. Additionally, I would like to acknowledge Dr. James E. Martin at Wayne State University for the data used in this paper and his support throughout the project. 
Acknowledgements i

List of Tables iv

List of Figures. . V

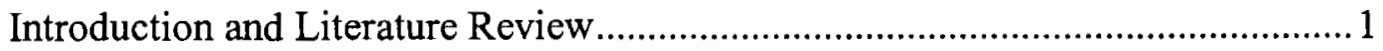

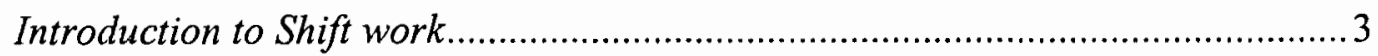

Health Effects of Shift Work .................................................... 3

Work Schedule Design ........................................................... 4

Tolerance to Shift Work .........................................................

Social/Family Outcomes of Shift Work....................................... 7

Individual and Organizational Outcomes of Shift Work ................ 8

Shift Work Interventions .................................................. 14

The Present Study ............................................................... 14

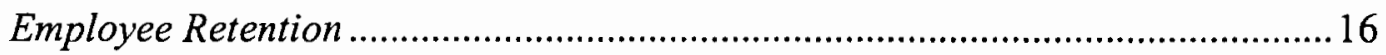

Psychological Mechanisms Accounting for the Shift Work-

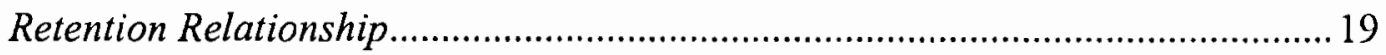

Commitment and Social Exchange ...........................................20

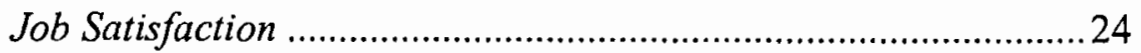

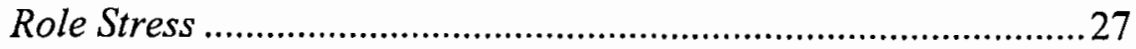

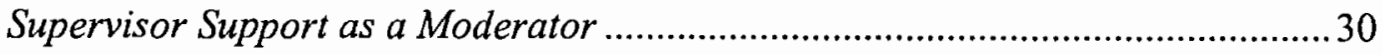

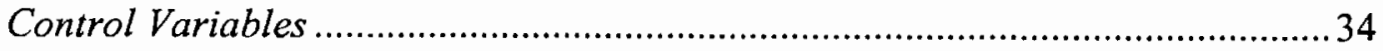

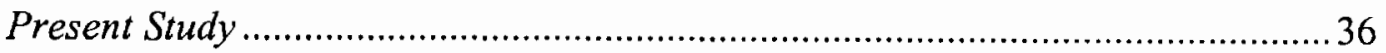


Method.

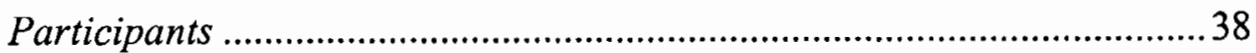

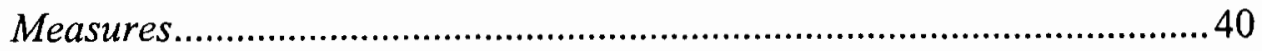

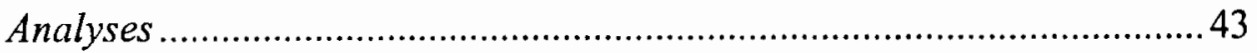

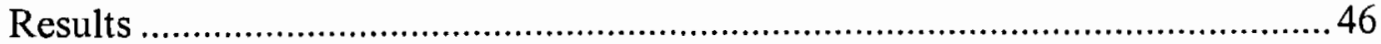

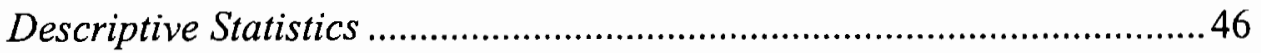

Tests of Hypotheses to Confirm Prior Research ...................................50

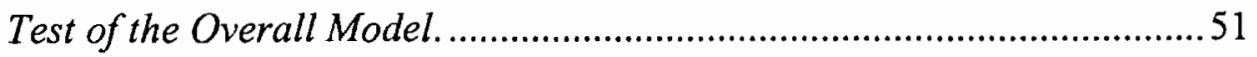

Commitment, Satisfaction, and Role Stress as Mediators .......................54

Test of Supervisor Support as a Moderator .......................................... 56

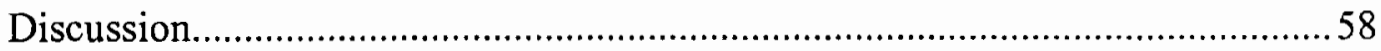

Limitations and Suggestions for Future Research ......................................... 73

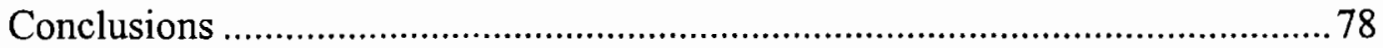

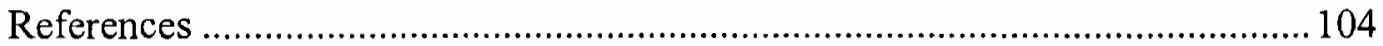

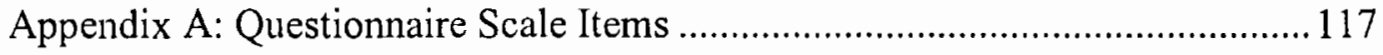

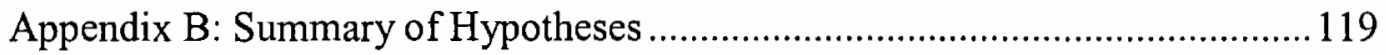




\section{List of Tables}

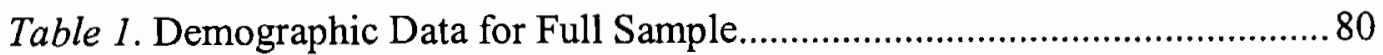

Table 2. Demographic Data for Sub-sample of Fixed Shift Employees ............... 82

Table 3. Means, Standard Deviations, and Correlations for Full Sample ............. 84

Table 4. Means, Standard Deviations, and Correlations for Sub-sample ............. 85

Table 5. Mediation Analyses for Mixed versus Fixed Shift..............................8 86

Table 6. Mediation Analyses for Morning versus Night Shift ........................... 87

Table 7. Mediation Analyses for Evening versus Night Shift ............................. 88

Table 8. Mediation Analyses for Morning versus Evening Shift ...................... 89

Table 9. The Interaction between Mixed versus Fixed shift and

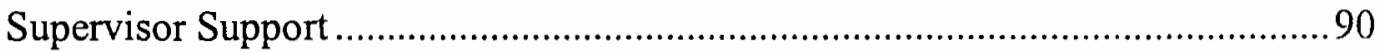

Table 10. The Interaction between Individual Shifts and Supervisor Support

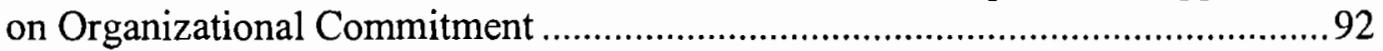

Table 11. The Interaction between Individual Shifts and Supervisor Support

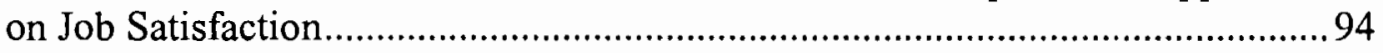

Table 12. The Interaction between Individual Shifts and Supervisor Support

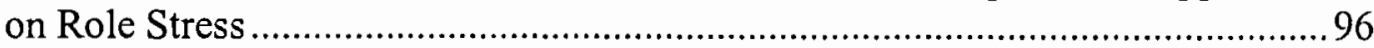




\section{List of Figures}

Figure 1. Proposed Theoretical Model....................................................... 98

Figure 2. Standardized Regression Coefficients for Mixed vs. Fixed Shift .........99

Figure 3. Results of Full Model for Morning vs. Night Shift .......................... 100

Figure 4. Results of Full Model for Evening vs. Night Shift.......................... 101

Figure 5.Results of Full Model for Morning vs. Evening Shift ...................... 102

Figure 6.Interaction between Morning versus Evening Shift and Supervisor

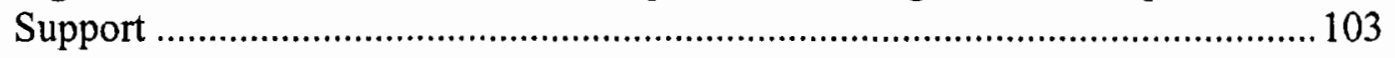


Introduction and Literature Review

Organizational psychology studies often focus on employees who work traditional (9-5, Monday-Friday) shifts. However, as the nature of the U. S. economy changes, an increasing number of employees work non-standard shifts, including evening and night shifts as well as irregular work schedules that might include a mix of different shifts. The increasing demand for non-standard work is related to three factors; changing economy, changing demographics, and changing technology (Presser, 2003). Shift work is increasingly prevalent in the manufacturing and service industries, which often operate on a 24 hour basis (Presser, 1995). In addition, as many as half of employees who work non-standard hours hold white collar jobs in industries such as healthcare, technology, and customer service (Circadian Technologies, 2003). Presently, more than 17 percent of the full-time workforce and 36 percent of the part-time workforce in the United States works non-standard schedules (Beers, 2000). Employees work non-standard schedules for various reasons, including complying with job requirements, to obtain greater compensation (i.e., shift premiums), to alleviate non-work conflicts (e.g., sharing child care responsibilities), and because they are unable to find other jobs with more desirable work schedules.

In 1977, Randall Dunham wrote an article in the Academy of Management Review emphasizing that very little research had been conducted on the psychological and organizational effects of shift work. Presently, 26 years later, there is still a lack of research examining the connection between work schedules and organizational outcomes. The goals of this study are to examine how shift work influences 
employees' experiences at work, and how these experiences lead to meaningful organizational outcomes. This paper contains a summary of current shift work literature, including work schedule design, individual and organizational outcomes, and interventions. Additionally, I review literature and theory to support the notion that shift work may influence affective commitment, job satisfaction, role stress, turnover intentions, and retention.

The present study focuses on employees in a large retail organization. Retail organizations may feel pressure to operate on a twenty-four hour basis due to increased competition, with more and more organizations extending their hours (McIntyre, 1988). I test a model that hypothesizes that retail workers on mixed shift schedules will report lower levels of organizational commitment and job satisfaction and higher levels of role stress than workers on fixed shift schedules. I also test the same model for differences between morning, evening, and night shifts, hypothesizing that night shift employees will report lower levels of commitment and satisfaction and higher role stress than morning or evening shift workers. Furthermore, I predict that low levels of reported organizational commitment and job satisfaction, and high levels of role stress will lead to increased intentions to turnover, and ultimately influence retention. Finally, I examine the moderating role of supervisor support on the relationships between shift work and commitment, job satisfaction, and role stress (Figure 1 presents the proposed model). I drew on several different theories to develop my model, including Social Exchange Theory, the Demand-Control-Support theory of 
organizational stress (Karasek \& Theorell, 1990), and Mobley's Theory of Turnover (1977).

Introduction to Shift Work

The Handbook of Occupational Health Psychology defines shift work as "... any arrangement of daily working hours that differs from the standard daylight hours" (Smith, Folkard, \& Fuller, 2003, p. 163). Organizations use a variety of scheduling patterns depending on the nature of the work and their production goals. An employee's work schedule can be defined in terms of combinations of status (fulltime or part-time), hours (number of hours worked), shift (time the hours are worked), and schedule (combination of hours and shifts worked) (Holtom, Lee, \& Tidd, 2002).

In my review of the shift work literature, several major themes emerged. These include the health effects of shift work, work schedule design, tolerance to shift work, family and social outcomes, individual and organizational outcomes, and interventions. In the following sections I will review this literature.

Health Effects of Shift Work

Shift workers are often considered to be at greater risk for physical and psychological problems than those working standard hours (Costa, 1996). Over time, work schedules can have a cumulative negative affect on employee health (Bourdouxhe et al., 1999). Shift work, specifically night work and mixed shift schedules, has been associated with sleep deprivation, fatigue, gastrointestinal 
disorders, cardiovascular disorders, and women's reproductive disorders (for a review see Smith, Folkard, \& Fuller, 2003).

Work Schedule Design

Several work schedule designs have been addressed in shift work literature, including comparisons of night versus day work (Blau \& Lunz, 1999; Furnham \& Hughes, 1999), fixed versus mixed schedules (Knauth, 1996), changeover times between shifts (Tucker, Smith, Macdonald, \& Folkard, 1998), and shift length (Pierce \& Dunham, 1992; Tucker et al., 1998). There is no "most" effective shift system because of individual schedule preferences and situational differences in the nature of the job (Snyder, 1995). Nonetheless, Knauth (1996) provides several suggestions for designing shift systems that include: reducing night work as much as possible; using forward rotation as opposed to backward rotation of shifts (working a morning than an evening shift instead of evening to morning); limiting the number of consecutive working days to between five and seven; including at least two consecutive days off; and including at least some weekends off (Knauth, 1996).

In this study, I examined two different aspects of work schedules. Fixed versus mixed work schedules refers to the level of regularity in a person's schedule. Fixed shift schedules are those in which the employee works the same hours at the same times from week to week. Mixed schedules occur when employees' schedules change from week to week or when they work different shifts within the same week. This type of shift schedule can include a regular rotating or a completely random schedule. I also explored differences between the actual shifts employees work, including 
morning, evening, and night shifts. For these analyses, I examined a subset of the population who work only one shift to determine if there are any meaningful differences based on the time of day an employee works.

\section{Tolerance to Shift Work}

Individual differences may moderate the effects of shift work on health.

Certain individuals may have characteristics or engage in certain behaviors that reduce or exacerbate the negative effects of shift work. For example, regular sleeping patterns during the day, physical activity, and social interaction may help ease the negative impacts of shift work (Furnham \& Hughes, 1999). Individuals who have a low tolerance for shift work often move to jobs that do not require them to work nonstandard hours.

Shift workers with inflexible sleeping habits and greater workloads experience increased sleep disturbances regardless of shift type (C. S. Smith et al., 1999). Nurses who prefer the night shift may be more flexible in their sleeping habits and exhibit a preference for staying up late and sleeping in (Barton, 1994). "Morningness" (morning-evening orientation) has been defined as a preference for activities in the extremes of the day, either early in the morning or late at night (C. S. Smith et al., 2002). Morningness is characterized by rigidity in sleep habits (Hildebrandt \& Stratmann, 1979; C. S. Smith, Folkard, \& Fuller, 2003) and may be related to shift work tolerance (C. S. Smith et al., 2003), as these individuals may adapt better to nonstandard schedules. 
Positive and negative affective dispositions have also been examined as possible influences of shift work tolerance (Prizmic \& Kaliterna, 1995). Reports of digestive problems and cardiovascular disease are higher in participants with high negative affectivity and low positive affectivity. Measures of positive affectivity and negative affectivity were significantly related to a set of tolerance for shift work measures (Prizmic \& Kaliterna, 1995). Negative affectivity, measured by neuroticism, also has been related to higher psychosomatic complaints and psychological distress in shift workers (Parkes, 1999).

In addition to individual differences, several studies have shown that preference for shift and level of choice involved in schedule design may influence the relationship between shift work and various outcome variables. Barton (1994) found that nurses who chose to work permanent night shifts reported fewer health, sleep, and social problems than those who did not prefer the night shift. Furthermore, scheduling control has been positively related to higher levels of commitment and satisfaction, and lower levels of burnout (Krausz, Sagie, \& Bidermann, 2000). Some employees may choose to work at night because they are working multiple jobs (Baba \& Jamal, 1992) or because night work allows them to spend time with their family during the day (Barton, 1994).

Although all of these factors are important to shift work research, none of them were directly measured in the present study. The sample is large, and includes participants from a variety of different demographic and situational backgrounds. However, it is important to acknowledge these potential influences when drawing 
conclusions about the results. Future research should explore the effects of these variables on the individual and organizational outcomes of shift work.

Social/Family Outcomes of Shift Work

There are mixed results concerning the effects of non-standard work schedules on an employee's family and social life. However, most research indicates a negative relationship. Data from the National Survey of Families and Household indicates that among married couples, $11.4 \%$ of husbands and $8.1 \%$ of wives worked non-standard shifts (Presser, 2000). Khaleque (1999) found that the majority of rotating shift workers perceived that their work schedules disturbed family and social life, leisure activities, and mealtimes. However, Bourdouxhe et al. (1999) concluded that extended shifts ( 12 hours) did not result in work load-related conjugal or family problems.

Shift work has been linked to difficulty scheduling family activities, less time in family roles, and higher levels of work family conflict (Staines \& Pleck, 1984). Working non-standard schedules has also been associated with increased instance of separation and divorce for couples with children (Presser, 2003). Factors influencing the relationship between shift work and divorce include whether the wife worked night or rotating shifts, whether the couple had children, and the length of the couples' marriage (Presser, 1994). Interference with family may be one reason that mixed schedules and night work contribute to reduced organizational commitment and job satisfaction. Furthermore, having a variety of family roles in addition to work roles may cause employees to feel overloaded when they are at work. For example, an 
employee who has to work during a child's sporting event may experience role stress as a result of the conflicting role demands.

\section{Individual and Organizational Outcomes of Shift Work}

Fixed versus mixed schedules. One way to conceptualize shift work is the distinction between fixed and mixed schedules. Employees on fixed schedules work the same shift from week to week. In this study, I define mixed shift schedules as any schedule that involves working more than one shift. For example, rotating schedules occur when an employee's schedule changes from week to week at fixed intervals. A mixed schedule also can be a situation where a new schedule is made each week.

Mixed shift schedules can cause problems for employees because of circadian rhythm disturbances. Blau and Lunz (1999) state that "...the rotating shift typically suffers the most, with the fixed night shift a close second" (p. 933). Additionally, other research suggests the benefits of working a fixed schedule. For example, Jamal (1981) found that nurses working fixed schedules report better mental and emotional health, more job satisfaction, higher levels of social involvement, and stronger organizational commitment than those working a mixed schedule. Furthermore, Khaleque (1999) found that the majority of mixed shift workers perceived that their work adversely affected health. Jamal also found that nurses on fixed shifts reported fewer turnover intentions and were less likely to be absent or tardy than those working mixed shifts. In a similar study, Jamal and Baba (1992) concluded that mixed shift workers reported more job stress and turnover intentions, and less organizational commitment, job satisfaction, and work hours satisfaction than fixed shift workers. Pattanayak (2002) 
found that for supervisors in India, individuals working a three shift schedule reported lower levels of organizational commitment than those working a standard (9-5) schedule.

Mixed shift workers are more likely to be absent and have lower levels of intrinsic motivation than permanent day workers (Jamal \& Baba, 1997). Additionally, mixed shift workers have reported feeling that their work schedules disturbed their family and social life, leisure activities, mealtime, and sleep, and adversely affected their health (Khaleque, 1999). Jamal (1981) suggests that these effects may occur due to the lower level of routinization in rotating schedules. Mixed shift workers may also become more fatigued than employees working a fixed shift. Finally, nurses working mixed schedules have twice the odds of a reported accident or error related to sleepiness (Gold et al., 1992).

In the present study, I assume that employees will prefer working a fixed shift to working a mixed shift. Jamal (1981) argues that a fixed schedule allows employees to attend social activities, fulfill family responsibilities, and cope with physical and mental fatigue. Working a schedule that changes every week also can make it difficult to plan ahead for non-work activities. Furthermore, in some cases, the number of hours an employee works may change from week to week, depending on the needs of the organization. Based on this research it appears that fixed shift workers should report higher organizational commitment and job satisfaction and lower role stress than mixed shift workers. 
Individual shifts. Due to recent changes in the United States economy, night work is becoming increasingly more common (Barton, 1994). In terms of shift work research, the majority of studies include night work in some fashion. Night work presents a unique set of considerations for employees, such as increased risk of occupational violence (Salminen, 1998), affective disturbances such as loneliness and irritation (Bohle \& Tilley, 1998), poor sleep quality (Bourdouxhe et al., 1999; Parkes, 2002), socia1/domestic problems (Presser, 2000), and accidents (Williamson \& Feyer, 1995). Employees working night shifts may also have less job discretion and greater exposure to physical work conditions (e.g. noise, poor air quality) than their day working counterparts in the same job (Parkes, 1999).

Night work can be a permanent shift, or part of a rotating shift system. A fixed shift means that individuals work only at night, and a mixed schedule includes some night shifts as well as day shifts. There is debate in the literature concerning the advantages and disadvantages of fixed and mixed night work schedules. Permanent night shift work may be more desirable because it allows an employee's circadian rhythm to adjust to a nocturnal schedule (Barton, 1994). For example, Barton found that nurses working permanent night shifts reported fewer health, sleep, social, and domestic problems than nurses working mixed schedules. However, a full adjustment is often difficult or impossible to accomplish, and a quickly rotating system, with as few night shifts as possible, may be preferable (Knauth, 1996).

Changeover times of shifts, especially between night shifts, can influence the effects of night work on employees. Tucker et al. (1998) found that for employees 
working in the early morning, starting work later allows individuals to get more sleep, since most people go to bed at the same time regardless of when they have to get up. However, for individuals who sleep during the day, early changeovers are more favorable. Getting off work later may cut afternoon sleeping short because of children, housework, and other daytime distractions. Providing employees with some flexibility for beginning and ending times of shifts when possible can help accommodate individual preferences for changeover times.

One of the most heavily studied topics concerning shift work and health is sleep deprivation and circadian rhythm disturbances. Disrupted sleep and circadian rhythm patterns can lead to several other health consequences, including fatigue and gastrointestinal problems. Human circadian rhythms generally function on a twentyfour hour cycle, based on a light-dark cycle. Working non-standard schedules can disrupt the body's natural cycle (C. S. Smith et al., 2003). Khaleque (1999) found that different work schedules affected the quantity of sleep for both morning and evening types, with night workers sleeping the least number of hours. In another study, night working nurses were 1.8 times more likely to report poor quality sleep than day or evening shift nurses (Gold et al., 1992). This lack of sleep can be a result of internal disruptions to the circadian rhythm or external disruptions such as light outside or loud children. These sleep disturbances led to frequent lapses of attention, increased reaction time, and increased error rates on performance tasks (Khaleque, 1999). Increased sleepiness may cause night workers to be more prone to accidents (Akerstedt, 1995). Furthermore, accidents and injuries that occur during night shifts 
are typically more severe than those occurring during the day (L. Smith, Folkard, \& Poole, 1994).

Parkes (2002) conducted a study of both onshore and offshore oil rig workers. This study is unique, because the onshore workers went back to the "real world" after work, where the offshore workers were sheltered from most non-work conflicts during a certain work period. Parkes found a significant three-way interaction between the effects of individual differences (age, smoking, negative affect), shift (day shifts, night shifts, leave periods), and environment (offshore vs. onshore) on sleep duration and quality. Onshore workers differed in their sleeping patterns across work phases (shifts) by age, smoking, and negative affectivity, however these effects were not found for offshore workers. Parkes suggests that the nature of the offshore environment may help employees adapt their circadian rhythms, which results in better sleep. In this sheltered environment, individual differences do not impact sleep quality. Main effects were found for sleep quality and age, with adaptation to night work becoming more difficult with age, although this effect leveled off at 45 years. Further, smokers reported higher sleep quality than non-smokers, but less sleep duration. Neuroticism was significantly and negatively related to sleep quality, but not shift duration. Finally, sleep quality was best during leave periods and worst for night shift (Parkes, 2002). Results from this study support the notion that both individual and environmental characteristics influence the outcomes associated with working different shifts.

There also is evidence that individuals working night shifts may engage in poorer health behavior than day workers. For example, missing meal times and lack of 
availability of healthy food may lead to unhealthy eating habits. Thus, it is not surprising that shift workers are 1.5 times more likely to be overweight than day workers (Kivimaki, Kuisma, Virtanen, \& Elovainio, 2001). In addition, workers may smoke or consume large amounts of caffeine to stay awake during night or early morning shifts. Shift workers with disrupted sleep patterns may consume alcohol in greater quantities to help them fall asleep after a shift (Kivimaki, et al., 2001). In a study of Canadian workers, men who worked an evening shift were more likely to be daily smokers than those working day shifts (Shields, 2002). High instances of overweight shift workers may be due their diet and disturbances of gastrointestinal and psychophysiological functioning (Kivimaki, et al., 2001).

Shift work has also been linked to psychological problems. For example, Healy, Minors, and Waterhouse (1993) proposed that shift work might lead to a certain amount of learned helplessness, which can lead to depression. Participants who made an external attribution to the temporary stress of shift work had more intense emotional responses and more psychosomatic complaints. These affective responses were strongest following night shift work (Healy et al., 1993). However, in a conflicting study, Goodrich and Weaver (1998) found no relationship between shift work and depression. Working evening shifts has also been related to psychological distress (Shields, 2002). Thus, although some evidence suggests a link between shift work and psychological problems, more research is needed in this area.

The present study compares permanent night shift workers to permanent morning and evening shift workers. Based on the current literature, I posit that night 
shift workers will report more negative outcomes than morning or evening shift workers. Night work may result in negative effects for employees, due to poor sleep quality (Bourdouxhe et al., 1999; Parkes, 2002) and social/domestic conflicts resulting from working at night and sleeping during the day (Presser, 2000).

Shift Work Interventions.

Several interventions have been suggested to help individuals deal with the negative effects of shift work. Some shift work interventions revolve around the concept of "tricking" the body's natural rhythm; including prescription sleep aids and placing bright lights in the work environment. Some organizations also use education and counseling programs to assist individuals with shift work adaptation (C. S. Smith et al., 2003). Another approach to curbing the negative effects of shift work is to examine the nature of the work environment itself, as well as the policies and procedures used to design schedules. Although there is great potential in these methods, little research has been conducted to evaluate these programs.

\section{The Present Study}

Current shift work literature consists mostly of studies examining the physical health effects of shift work, schedule design, and work and family issues surrounding shift work. Furthermore, much of the research has been conducted outside the United States (U. S.), where regulations and norms around work schedules may be different than in the U.S. My study addresses some of the gaps in shift work research, specifically looking at the organizational outcomes of shift work. Focusing on the organizational aspects of shift work can lead to programs that improve working 
conditions for employees and reduce costs for organizations. Another gap in the literature is the study of retail workers. Much of current the shift work research focuses on the health care industry, specifically with nurses. However, with shift work becoming increasingly common, more research is needed in other industries. Retail is one industry that is increasingly using twenty-four hour labor. The increase of shift work, specifically night work, in other industries has created a greater need for goods and services to be available on a twenty-four hour basis. The findings of this study will contribute to current shift work literature by examining organizational outcomes of shift work in a retail setting.

I examine two types of shift work arrangements in the present study, fixed versus mixed schedules and a comparison of day, evening, and night work. Based on the literature presented above, I posit that working mixed work schedules and solely at night will result in negative organizational outcomes. Neither the morning nor the evening shifts in this study fall into the category of a "standard" shift. The morning shift begins at 6:00 a.m. and goes until 2:00 p.m. The evening shift begins at 2:00 p.m. and ends at 10:00 p.m. Therefore, I will examine, but have not proposed specific hypotheses concerning, the differences between morning and evening shift work. Past research indicates that both mixed schedules and night work result in negative employee and organizational outcomes (Folkard, Akerstedt, Macdonald, Tucker, \& Spencer, 2000; Jamal, 1981; Jamal \& Baba, 1997). However, it is important to note that some employees may prefer working night or mixed shifts for a variety of reasons. Although this may be true in some cases, several of the studies I have 
reviewed have not included schedule preference and have obtained significant results. Therefore, I posit that for the majority of workers, night work and mixed schedules are less favorable than morning or evening work and fixed schedules.

Employee Retention

Employee turnover costs organizations millions of dollars each year in areas such as recruiting and training new employees, administrative costs, separation benefits, and lost productivity (Griffeth \& Hom, 2001). Predicting turnover can be a difficult undertaking because of a lack of consensus in the literature and a variety of moderation and mediation processes involved in predicting turnover. Further, a wide range of individual and organizational factors influence turnover. Turnover in this study will be measured by employee retention. Retention is the inverse of turnover, capturing the individuals who have remained with the organization, rather than those who have left. Although most research uses turnover, employee retention provides subsequent length of employment from a given point in time, which provides more information that a dichotomous turnover variable. Retention is an important variable to study, since the goal of most organizations is to retain employees (reduce turnover). This study will focus on work schedules as an organizational factor that influences retention through its influence on affective commitment, job satisfaction, and role stress.

Cotton and Tuttle (1986) conducted a meta-analysis examining the precursors to voluntary turnover. Several work-related factors, including compensation, job satisfaction, and commitment are strongly related to turnover. Performance, co- 
workers, promotions, and role clarity are also significantly, though not as strongly, related to turnover (Cotton \& Tuttle, 1986). In a more recent meta-analysis, low job satisfaction, low organizational commitment, increased job search behaviors, comparison of employment alternatives, withdrawal conditions, and quit intentions were found to be the best predictors of turnover (Griffeth, Hom, \& Gaertner, 2000). Job content, stress, lack of work group cohesion, and lack of autonomy are significant but somewhat weaker predictors. The mixed results across this long list of predictors demonstrate the complexity involved in studying turnover and retention.

Several theories have been presented to explain employee turnover. March and Simon (1958) suggested that the equilibrium between employee contributions and organizational inducements determines an individuals' likelihood to leave the organization through two mechanisms. First, the perceived desirability of movement is based on an individual's satisfaction with the job, which depends on the conformity of job characteristics to self-image, the predictability of job relationships, and the compatibility of the job with other roles. Second, the availability of opportunities within the organization influences the perceived desirability of movement. March and Simon also proposed that the perceived ease of movement influences employee turnover. The ideas presented in this theory are foundations of current turnover theory (Hom \& Griffeth, 1995).

Mobley (1977) presented a model to explain the intermediate linkages between employees' evaluations of their job and subsequent turnover. According to this model, a negative evaluation of the job results in job dissatisfaction. At this point, an 
employee is said to think about quitting, analyze the utility and costs associated with quitting, intend to quit, actually seek, and to evaluate other job alternatives, including comparing alternatives to the current job. Finally, the employee will make a quit decision. Mobley, Horner, and Hollingsworth (1978) tested the model on a sample of hospital employees and found empirical support for the model. This model has been extremely influential on current turnover theories, and there have been many other extensions of the original model (Lee \& Mitchell, 1994; Muchinsky \& Morrow, 1980). Furthermore, research has shown that this model can be extended to use attitudinal commitment to predict turnover (Mathieu \& Zajac, 1990).

Some of the key concepts in the Mobley (1977) model are the psychological processes that occur between the time an employee begins to think about quitting and when that individual ultimately decides whether to leave the job. Intention to turnover is a widely used construct in turnover research; both as an intermediate linkage variable and an outcome variable when actual turnover data are not available. In support of this usage, turnover intentions were found to be strong predictors of turnover in recent meta-analyses (Cotton \& Tuttle, 1986; Griffeth et al., 2000). Furthermore, Tett and Meyer (1993) found that the relationship between affective commitment and turnover was mediated through turnover intentions. In their examination of model, Mobley and colleagues (1978) found that intention to turnover was the only significant predictor of actual turnover.

In this study, intention to turnover will be included as an intermediate linkage between commitment, job satisfaction, and role stress, and retention. Employees who 
are experiencing low levels of job satisfaction or organizational commitment, or high levels of stress, also should report intentions of leaving an organization before they formally resign. These hypotheses are intended to confirm prior research and theory, rather than contributing new findings to the field.

Hypothesis 1: Individuals with stronger turnover intentions will be less likely to remain with the organization.

Hypothesis 2a: Intention to turnover will mediate the positive relationship between organizational commitment and retention.

Hypothesis $2 b$ : Intention to turnover will mediate the positive relationship between job satisfaction and retention.

Hypothesis 2c: Intention to turnover will mediate the negative relationship between role stress and retention.

Psychological Mechanisms Accounting for the Shift Work-Retention Relationship Based on the Mobley Turnover Model, I posit that individuals go through a quasi-rational decision-making process when making a quit decision. It is important for researchers to understand the processes that might cause certain individuals to leave the organization. Working a non-standard schedule may cause employees to experience a decrease in commitment to their organization, dissatisfaction with their job, or feelings of role overload. Through a series of cognitive processes, problems created by unsatisfactory schedules may ultimately lead to voluntary turnover. Job satisfaction relates to the nature of the actual job, while commitment is focused on the global organization (Tett \& Meyer, 1993). Commitment, job satisfaction, and role 
stress are affective and cognitive responses that influence behavior. Considering organizational commitment, job satisfaction, and role stress separately may provide evidence concerning which process links shift work to intention to turnover and retention.

\section{Commitment and Social Exchange}

Meyer, Allen, and Smith (1993) define commitment as a psychological state that reflects the relationship employees have with their organization and that affects their decision to continue membership in the organization. Commitment has been studied widely as both an antecedent and a consequence of other worker-related variables, such as job performance, union commitment, and intentions to leave (Mathieu \& Zajac, 1990). Affective commitment is defined as an employee's identification with, involvement in, and enjoyment of membership in the organization (Meyer \& Allen, 1991). Although affective commitment is influenced by personal characteristics, organizational structure, and work experiences, recent research suggests that work experiences are largely responsible for determining affective commitment, as well as employees' desires to maintain membership in an organization (Meyer \& Allen, 1991). Thus, there is reason to expect that working a mixed schedule or night work should influence affective commitment.

Researchers often use Social Exchange Theory to explain how work experiences influence affective organizational commitment (Wayne, Shore, Bommer, \& Tetrick, 2002). Social exchange theory is related to equity theory, which states that humans tend to view social interactions as similar to economic transactions, in terms 
of the balance between what is given and what is received (Homans, 1958).

Employees evaluate the fairness of these exchanges based on their perceptions of the inputs they bring to the organization and the outcomes they receive from the organization (e.g. pay, positive work environment). Furthermore, Social Exchange Theory posits that resources given by others are valued more when the act is discretionary, because voluntarily sharing such resources is interpreted as an indication that the contributor values and respects the recipient. The perception of positive treatment creates a felt obligation in the employee to help the organization reach its objectives (Rhoades, Eisenberger, \& Armeli, 2001). When employees perceive their organization's policies (e.g. promotion decisions or job conditions) as being positive and a result of the organization's choice, they are more likely to remunerate the organization with positive attitudes and behavior (Rhoades \& Eisenberger, 2002). One way this happens is when employees reward the organization with higher levels of commitment.

In the present study, work schedules will be considered as a work experience that helps define an employees' social exchange relationship with their employers, and in turn influences their affective commitment. Shift work has been linked to organizational commitment for mid-level supervisors (Pattanayak, 2002). Jamal and Baba (1992) found that nurses working fixed shifts had higher levels of organizational commitment than those working rotating shifts. When individuals work a variety of different shifts, the demands of the job may be different and the employee may experience negative consequences, such as increased work-family conflict (Blau \& 
Lunz, 1999; Khaleque, 1999). These negative experiences may lead employees to perceive a low level of support from their organization. I predict that employees will view mixed work schedules and night work less favorably than fixed or day or evening shift schedules. Employees who work more favorable shifts may see their schedules as positive inducements from the organization. Therefore, these employees will be more likely to reciprocate with high levels of affective organizational commitment.

Hypothesis 3: Employees working a mixed shift schedule will report less affective organizational commitment than employees working a fixed shift schedule.

Hypothesis 4a: Employees working night shifts will report less affective organizational commitment to their organization than employees working morning shifts.

Hypothesis 4b: Employees working night shifts will report less affective organizational commitment than employees working evening shifts.

Hypothesis 4c: Employees working morning shifts will differ in their levels of affective organizational commitment from employees working evening shifts.

Several meta-analyses have revealed that employee commitment is linked to absenteeism, turnover intentions, and turnover (Eby, Freeman, Rush, \& Lance, 1999; Griffeth et al., 2000; Mathieu \& Zajac, 1990). This research confirms that employees who are committed to their organization have stronger desires to remain employed with that organization. Evidence also suggests that the relationship between 
organizational commitment and employee turnover is stronger for individuals in white-collar positions than traditional blue-collar positions (Cohen \& Hudecek, 1993). However a study of retail workers indicated that organizational commitment had a strong negative relationship with intention to leave (Good, Sisler, \& Gentry, 1988). Employees who reported higher levels of organizational commitment were less likely to report intentions to leave the organization. Based on this research, I posit that lower levels of organizational commitment will be associated with increased intention to turnover.
Hypothesis 5: Employees who report lower levels of affective commitment will report stronger tumover intentions that those who report high levels of commitment.

Research highlighting the effects of shift work on commitment (Jamal \& Baba, 1992; Pattanayak, 2002) and the link between commitment and turnover intention (Griffeth et al., 2000; Mathieu \& Zajac, 1990) suggests that commitment mediates the relationship between shift work and turnover intention. Employees who work mixed work schedules or at night may be less committed to their organization. This lack of commitment may lead the employees to consider leaving the organization. Therefore, I predict that individuals who work more favorable schedules may reciprocate with higher levels of commitment, and individuals who feel stronger commitment to their organizations will be less likely to report intentions to turnover.

Hypotheses 6: Organizational commitment will mediate the relationship between mixed versus fixed shift work and intention to turnover. 
Hypothesis 7a: Organizational commitment will mediate the relationship between morning versus night work and intention to turnover.

Hypothesis $7 b$ : Organizational commitment will mediate the relationship between evening work versus night work and intention to turnover.

Hypothesis 7c: Organizational commitment will mediate the relationship between moming versus evening work and intention to turnover.

\section{Job Satisfaction}

Locke (1976) defined job satisfaction as “...a pleasurable or positive emotional state resulting from the appraisal of one's job or job experiences" (p. 1300). Job satisfaction represents the extent to which employees like or dislike their job (Spector, 1997 ) and can be general or facet-specific (Tett \& Meyer, 1993). Job satisfaction is influenced by job characteristics, work-family conflict, job stress, work overload, work schedules, and a variety of individual variables (Spector, 1997). Although job satisfaction is used in many studies, few good theories exist to explain its antecedents and consequences (Brief, 1998). One category of job satisfaction theories have been defined as situational theories (Judge, Parker, Colbert, Heller, \& Ilies, 2001).

Situational theories posit that the nature of one's job or other aspects of the work environment determine job satisfaction. Although none of the theories in this category (i.e. Herzberg's two factor theory, job characteristics theory) apply to the variables in my study, the notion that work environment influences job satisfaction has been supported in the literature (Spector, 1997). Therefore, this study considers work schedules as one of the many work experiences that influence global job satisfaction. 
Individuals who are unhappy with their shifts tend to report less job and life satisfaction (Zedeck, Jackson, \& Marca, 1983). Shift work has been linked to job dissatisfaction with individuals working at night being less satisfied then their day and evening working counterparts (Furnham \& Hughes, 1999; Jamal \& Baba, 1997). Furthermore, Jamal and Baba found that rotating shift workers were less satisfied than fixed shift workers (1992). One reason for this dissatisfaction may be that the nature and conditions of specific jobs differ between individuals working different shift schedules. For example, day shift workers often have more skill variety, task identity, task significance, autonomy, and feedback than evening, night, or rotating shift workers (Blau \& Lunz, 1999). In addition, shift workers report higher levels of exposure to adverse environmental conditions, less job control and skill discretion, and lower safety perceptions than day workers (Parkes, 2003). These results suggest that there may be job differences between day and evening or night shifts, as well as mixed and fixed shift schedules.

I suggest that workers on schedules generally regarded as less satisfying (mixed shift schedules and night work) will be more likely to experience global job dissatisfaction. Employees working different schedules may be dissatisfied because of their schedule or because of work characteristics of a particular shift. For example, an employee working night shifts may not like their job because they have less customer interaction. Furthermore, an employee who works a mixed schedule on many different shifts may be dissatisfied with the instability of the schedule and their inability to plan things in their non-work lives. Therefore I posit that fixed shift workers will be more 
satisfied than mixed shift workers, and day and evening shift workers will be more satisfied than night shift workers.

Hypothesis 8: Employees working a mixed shift schedules will report less job satisfaction than employees working a fixed shift schedule.

Hypothesis 9a: Employees working night shifts will report less job satisfaction than employees working morning shifts.

Hypothesis $9 b$ : Employees working night shifts will report less job satisfaction than employees working evening shifts.

Hypothesis 9c: Employees working morning shifts will differ in their levels of job satisfaction from employees working evening shifts.

Although job satisfaction and organizational commitment are often highly correlated, they seem to contribute uniquely to the turnover process (Tett \& Meyer, 1993). The Mobley Turnover Model (1977) posits that job dissatisfaction is the first step in the turnover process. When employees become unhappy in their job situation, they begin to consider other employment options. The discussion on the negative outcomes of working non-standard shifts, suggests that shift work may cause dissatisfaction that will in turn lead to turnover intentions. Indeed, in their metaanalysis of turnover antecedents, Cotton and Tuttle (1986) concluded that job satisfaction was a stable and reliable predictor of turnover. Tett and Meyer (1993) found that intention to turnover was predicted more strongly by satisfaction than by commitment. These results suggest that withdrawal behaviors represent rejection of the job rather than the organization. 
Hypothesis 10: Employees who report lower levels of job satisfaction will have stronger turnover intentions than those who report high levels of job satisfaction.

Job satisfaction may also be a key mediating variable between work environment and turnover intent (Lambert, Hogan, \& Barton, 2001). Mobley et al. (1978) found that satisfaction was a significant predictor of intention to quit. It appears that when employees are dissatisfied with their jobs, they go through a cognitive process of intending to leave before they actually do so.

Hypothesis 11: Job satisfaction will mediate the relationship between mixed versus fixed shift work and intention to turnover.

Hypothesis 12a: Job satisfaction will mediate the relationship between morning versus night work and intention to turnover.

Hypothesis 12b: Job satisfaction will mediate the relationship between evening versus night work and intention to turnover.

Hypothesis 12c: Job satisfaction will mediate the relationship between morning versus evening work and intention to turnover.

\section{Role Stress}

The final mechanism that will be examined as a link between shift work and tumover is role stress. Shift work can be viewed as one of many stressful work conditions (i.e., lack of autonomy, time pressure) that can ultimately create strain for employees (Olsson, Kandolin, \& Kauppinen-Toropainen, 1990). Shift work can be considered a stressor because it is a work condition that requires an adaptive response 
by the employee and has similar health outcomes to other occupational stressors (Taylor, Briner, \& Folkard, 1997). Research suggests that psychological and physical stress develop when work schedules disrupt employees' biological functions, family and social life, and sleep (C. S. Smith et al., 2003).

In this study, I posit that mixed shift schedules and night work will create role overload, which is conceptualized as a stressor for employees. An employee's role can be defined by the set of activities he or she is required to perform (Kahn, Wolfe, Quinny, Snoek, \& Rosenthal, 1964). Quantitative overload occurs when individuals are unable to meet the expectations of their roles because of a lack of available time. Qualitative role overload occurs when the individual does not have the skills and abilities to completed the task (Shaw \& Weekley, 1985). The present study focuses on the quantitative overload for the employee's work role.

Shift work has been linked to role ambiguity, role overload, and job stress (Jamal \& Baba, 1992), with fixed shift workers reporting lower levels than rotating shift workers. One can imagine that the nature of a specific job may differ across shifts. For example, the sample used in this study consists of union members from a large retail organization. The work setting for these employees is a large "supercenter" store including grocery and general merchandise. The nature of the work environment and job demands changes throughout the day. In addition, the tasks employees are required to perform on the job may vary throughout the day. Furthermore, scheduling conflicts between work and non-work demands and fatigue all can lead to increased 
role stress. These factors may contribute to increased role stress for employees working multiple shifts or night work.

Hypothesis 13: Employees working a mixed shift schedule will report more role stress than employees working a fixed shift schedule.

Hypothesis 14a: Employees working night shifts will report more role stress than employees working morning shifts.

Hypothesis 14b: Employees working night shifts will report more role stress than employees working evening shifts.

Hypothesis 14c: Employees working morning shifts will differ in their levels of role stress from employees working evening shifts.

If employees become too overwhelmed with their job, they may decide to leave for a less stressful position. Role stress also predicts intention to leave in retail employees (Good et al., 1988). Nurses experiencing higher levels of role conflict also express higher intentions to turnover (Hemingway \& Smith, 1999). High levels of emotional exhaustion have been linked to increased turnover (Wright \& Cropanzano, 1998). Taken together, this research indicates that experiencing numerous types of stress can cause employees to leave their current jobs. Based on this research, I posit that employees experiencing higher levels of role stress will be more likely to voluntarily leave the organization.

Hypothesis 15: Employees who report higher levels of role stress will report stronger turnover intentions than those who report lower levels of role stress. 
Role stress may also mediate the relationship between shift work and turnover intentions. The stress created by working a mixed shift or night work may cause an employee to experience increased levels of role stress (Jamal \& Baba, 1992), which in turn may result in increased intention to leave (Hemingway \& Smith, 1999).

Hypothesis 16: Role stress will mediate the relationship between mixed versus fixed shift work and intention to turnover.

Hypothesis 17a: Role stress will mediate the relationship between morning versus night work and intention to turnover.

Hypothesis $17 \mathrm{~b}$ : Role stress will mediate the relationship between evening versus night work and intention to turnover.

Hypothesis 17c: Role stress will mediate the relationship between morning versus evening shift and intention to turnover.

Supervisor Support as a Moderator

There are several possible differences in both employees and the work environment that may influence the relationships proposed above. I have included supervisor support as a moderator because it has been shown to influence social exchange relationships and perceived stress in employees. Supportive supervisors engage in activities such as facilitating career development, communicating effectively, providing emotional support and informational assistance, giving useful feedback, encouraging effective work practices, and treating employees with respect (Kidd \& Smewing, 2001). For many employees, supervisor support is one of the most important sources of assistance, with higher supervisor support usually resulting in 
less strain (Bliese \& Castro, 2000) and increased commitment (Kidd \& Smewing, 2001) and satisfaction (Griffin, Patterson, \& West, 2001; Kidd \& Smewing, 2001).

Regarding work schedules, a supportive work environment may help employees' cope with problems related to their schedules as well as other stressors that may be exacerbated by shift work (such as work/non-work conflict). For example, social interaction during night shifts has been found to ease the negative impact of night work (Furnham \& Hughes, 1999). Shift workers depend more on supervisors when they experience work-related stress than individuals who work standard schedules (Schmieder \& Smith, 1996).

Supervisor support also has been linked to organizational commitment and career resilience (Kidd \& Smewing, 2001). Individuals may form their perceptions of organizational support based on the treatment they receive from their supervisors (Eisenberger, Stinglhamber, Vandenberghe, Sucharski, \& Rhoades, 2002). For example, individuals who perceive their supervisors as giving them trust and authority on the job and providing feedback and goal setting are more committed to their organizations (Kidd \& Smewing, 2001). Figure 1 depicts the form of the proposed effects of supervisor support on the relationships between shift work and affective organizational commitment.

Hypothesis 18: The relationship between fixed versus mixed shift schedules and affective organizational commitment will be stronger for individuals with low levels of perceived supervisor support. 
Hypothesis 19a: The relationship between morning versus night shift work and affective organizational commitment will be stronger for individuals with low levels of perceived supervisor support.

Hypothesis 19b: The relationship between evening versus night shift work and affective organizational commitment will be stronger for individuals with low levels of perceived supervisor support.

Hypothesis 19c: The relationship between morning versus evening shift work and affective organizational commitment will be stronger for individuals with low levels of perceived supervisor support.

Supervisor support is related to higher levels of job satisfaction for retail employees (Babin \& Boles, 1996; Griffin et al., 2001). Dissatisfaction with shift work can be influenced by lack of social support from co-workers and family (Bohle \& Tilley, 1998). Working in a supportive environment may also influence employee's feelings of well-being which can translate into job satisfaction (Babin \& Boles, 1996). The negative feelings about a job generated from working a non-standard schedule may not be as salient for individuals who feel supported by their supervisors. Working many shifts or working night shifts may be more tolerable for employees if they perceive higher levels of support from their supervisors. Figure 1 depicts the form of the proposed effects of supervisor support on the relationships between shift work and job satisfaction. 
Hypothesis 20: The negative relationship between fixed versus mixed shift schedules and job satisfaction will be stronger for individuals with low levels of perceived supervisor support.

Hypothesis 2la: The relationship between morning versus night shift work and job satisfaction will be stronger for individuals with low levels of perceived supervisor support.

Hypothesis $21 \mathrm{~b}$ : The relationship between evening versus night shift work and job satisfaction will be stronger for individuals with low levels of perceived supervisor support.

Hypothesis 21c: The relationship between morning versus evening shift work and job satisfaction will be stronger for individuals with low levels of perceived supervisor support.

The Job Demand-Control-Support model of stress suggests that social support buffers the effects of stress on employee well being (Johnson \& Hall, 1988; Karasek \& Theorell, 1990). In highly demanding jobs, increasing support may alleviate some of the negative consequences of strain (Dollard, Winefield, Winefield, \& de Jonge, 2000). Strong support from a supervisor may help buffer some of the negative effects associated with working many different shifts and night work. For example when supervisors communicate effectively, their employees may have a clearer understanding of job expectations. In addition, supervisors who have good relationships with their employees are more likely to be aware of scheduling conflicts and may be able to alter schedules accordingly. Figure 1 depicts the form of the 
proposed effects of supervisor support on the relationships between shift work and role stress.

Hypothesis 22: The positive relationship between fixed versus mixed shift schedules and role stress will be stronger for individuals with low levels of perceived supervisor support.

Hypothesis 23a: The relationship between morning versus night shift work and role stress will be stronger for individuals with low levels of perceived supervisor support.

Hypothesis 23b: The relationship between evening versus night shift work and role stress will be stronger for individuals with low levels of perceived supervisor support.

Hypothesis 23a: The relationship between morning versus evening shift work and role stress will be stronger for individuals with low levels of perceived supervisor support.

Control Variables

\section{Hours Worked}

Individuals who do not work many hours may be less affected by shift work. For instance, a study by Peters, Jackofsky and Salter (1981) demonstrated that thoughts of quitting and job satisfaction were related to turnover for full-time employees but not part-time employees. Part-time employees may not be as invested in their jobs (because they are more invested in other social systems such as family), and may leave once short range financial goals are met (Peters et al., 1981). 
Furthermore, predictors of turnover may be different for full-time and parttime employees. Job satisfaction, intentions to stay/leave, frequency of thoughts about quitting, expectations of finding alternate employment, and intentions to search predict turnover for full-time, but not part-time employees (Peters et al., 1981). In one study comparing part-time and full-time workers, differences were found only for individuals working certain full-time shifts (Lee \& Johnson, 1991). Another study found that both part-time and full-time employees who are dissatisfied with their schedules are more likely to voluntary leave the organization (Krausz et al., 2000). Since the employees participating in this study work anywhere from 3 to 70 hours per week, I will control for number of hours worked per week when investigating relationships between employee schedules and turnover. Age

Age may also be an indicator of shift work tolerance. Individuals who cannot tolerate shift work often leave for other jobs (Bourdouxhe et al, 1999). Older employees who remain in shift work may be those individuals who were able to adapt to working a non-standard schedule. Consequently, some research may under-estimate the negative health effects of shift work, especially night work (Kivimaki et al., 2001). To avoid selective dropout effects, I will control for age in this study.

\section{Weekend Work}

Members of the union sponsoring the survey have suggested that there also may be important differences between employees who worked a particular schedule 
during the week and those working the same schedule on the weekend. Therefore, I also controlled for whether the participants worked any weekend shifts.

\section{Children at Home}

Shift workers with children may differ in their reactions to their schedule from employees without children. For example, childcare concerns may influence an individual's preference for shift. Employees with children may be more likely to prefer night work, so they can be home with their children during the day. Women who have children are more likely to work nonstandard hours than those who do not, where there is no difference for men (Presser, 2003).

\section{Present Study}

Presently, there is a modest amount of research exploring the effects of shift work on organizational outcomes and the psychosocial processes that are influenced by shift work. The relationships between shift work and commitment, satisfaction, and role stress being examined in this study will contribute a new perspective to current shift work literature. While some relationships being examined are widely accepted, such as the link between intention to turnover and employee retention, the shift work portion of the study will make the greatest contribution to the literature. Findings related to the mechanisms linking shift work to retention can demonstrate the importance of work schedule design and may influence policies and procedures concerning work schedules. I also examine the influence of supervisor support on the relationships between shift work and commitment, satisfaction, and role stress. 
to reduce the negative impacts of non-standard work schedules. Examining how supervisor support influences these relationships may provide further insight into ways of preventing negative outcomes associated with shift work. I have proposed a model examining the effects of several shift work variables on organizational commitment, job satisfaction, and role stress, tumover intention, and retention (Figure 1). I test this model with four different shift work variables: fixed versus mixed shift schedules, mornings versus night shift work, evening versus night shift work, and morning versus evening shift work. A summary of the hypotheses tested in this study can be found in Appendix B. 


\section{Method}

Participants

Data for this study came from a large data set collected by Dr. James E. Martin of Wayne State University. The data were collected in conjunction with United Food Commercial Workers Union Local 951. The participants included union members who work for a mid-western retail chain. Union members completed the surveys in 1998, and retention data from union records were compiled during the following thirty-one months. Members received paper and pencil surveys at home and returned them by mail. In addition, 350 union stewards completed the survey during a forty-five minute period at a conference. Individuals entered into a raffle for several cash prizes as an incentive for completing the surveys. The participants worked in 14 job classifications; including cashiers, food clerks, and general merchandise clerks. A total of 29,618 surveys were sent out to employees working in fifty-eight stores in September of 1998 . Of these, $7,852(25.6 \%)$ returned the surveys, and 5,987 were matched to union records and included in the study. Subsequent retention data were collected every three months from November 1998 until February 2001. Individuals who were no longer on the union roster were considered to have left the organization.

To test my hypotheses, I used two different subsets of the data. First, I included 5,789 individuals in the analysis of mixed versus fixed shift. Of these, 3,511 worked only one shift and 2,278 worked more than one shift. To examine differences between shifts, I included only individuals who worked one, non-overlapping shift (e.g. shift 1, 2 , or 3$)(n=2,107)$. Of this group, 1,084 worked the day shift, 517 worked the 
evening shift, and 506 worked the night shift. Tables 1 and 2 present demographic information for both sets of data.

Martin and Sherman (forthcoming) compared respondents in this data set to the population of union members to assess the representativeness of the rank-and-file survey respondents. They found several significant differences $(p<.001)$. The sample was approximately five years older (39.1 years of age versus 33.8 ), had almost three years more seniority ( 7.9 years of seniority versus 4.9 ), and earned slightly more than $\$ 1$ an hour more than the total population. Additionally, compared to the population, the sample contained a higher proportion of females (69.3 percent versus 60.6 percent) and proportionately more full-time workers (50.6 versus 33.9 percent). Fifty-six percent of the employees in these 55 stores had left the union by February 2001. However, only thirty-nine percent of employees in the sample had left the union by this time. Therefore, the survey respondents were more representative of the employees who did not quit. Since the sample respondents had lower turnover than the organization as a whole, turnover may be underestimated in the sample.

There were also demographic differences within the sample between employees who remained with the organization and those that left. The employees who remained with the organization throughout this study (31 months) were significantly $(p<.001)$ younger than the sample by 2.6 years, less senior by 1.5 years, paid $\$ .84$ an hour less, 5 percent less likely to be female, and 8 percent less likely to be full-time. Since there appears to be some response bias, caution should be taken in predicting the generalizability of these findings to other populations. 
Measures

Shift worked. Respondents were asked to report all shifts they worked. There were twelve possible responses: Shift 1, Shift 2, Shift 3, Overlapping 1 and 2, Overlapping 2 and 3, and Overlapping 3 and 1. Each of these options was given separately for weekdays and weekends and respondents could check any option that applied. A copy of this and all other measures used in the study is provided in Appendix A. The day shift included hours worked anytime between 6:00 a.m. and 2:00 p.m. The evening shift hours were 2:00 p.m. to 10:00 p.m. and the night shift was between 10:00 p.m. and 6:00 a.m.

Affective commitment. Affective commitment was measured using a scale developed by Martin and Peterson (1987). The scale contained three items resembling previous organizational commitment scales (e.g., Meyer \& Allen, 1984, 1987;

Mowday, Porter, \& Steers, 1982). Respondents answered these questions on a sevenpoint agreement scale, with response options ranging from strongly disagree (1) to strongly agree (7). I averaged the responses on the three items to obtain a scale score. The internal consistency for the total scale was .88 for both the entire sample and the sub-sample.

Job satisfaction. The three-item, global measure of job satisfaction was developed by Camman, Fichman, Jenkins, and Klesh (1983). Respondents answered these questions on a seven-point agreement scale with response options ranging from strongly disagree (1) to strongly agree (7). I averaged the responses to the three items 
to obtain a scale score and the internal consistency for both the entire sample and the sub sample was .85 .

Role Stress. Dr. James Martin and Dr. Robert R. Sinclair developed the role stress questionnaire used in this study for the purpose of the original data collection. The scale contained four items assessing the concept of role overload. Respondents answered these questions on a seven-point agreement scale with response options ranging from strongly disagree (1) to strongly agree (7). I averaged the responses to the four items to obtain a scale score. The internal consistency for both the entire sample and the sub sample was .85 .

Supervisor support. Perceived supervisor support was measured by four questions relating to how an employee perceives their relationship with their immediate supervisor. The scale contained four items drawn from the Cammann et al. (1983) supervisor module as published in their Michigan Organizational Assessment Package. Respondents answered these questions on a seven-point agreement scale with response options ranging from strongly disagree (1) to strongly agree (7). Responses to each item were averaged to obtain a scale score. The internal consistency for both the total scale for the entire group and the sub-sample was .89 .

Intention to Turnover. Turnover intention was measured with three items adapted from Cammann et al. (1983). Respondents answered these questions on a seven-point agreement scale with response options ranging from strongly disagree (1) to strongly agree (7). Responses to each item were averaged to obtain a scale score. The internal consistency of the entire sample was .82 and for the sub-sample was .81 . 
Retention. Employees were tracked over a period of two and half years for their employment with the organization. Every three months, data were collected from the union roster and anyone no longer on the roster was considered to have left the organization. This procedure produced a score for each individual of the total months they remained employed. All respondents $(61 \%)$ who had not quit as of February 2001 were assigned a score of 31 months. Scores between 1 and 28 months were given to those who left, with higher scores for those who remained with the organization longer. The union officers noted that the major employer expansion during the period of the study (i.e., September 1998 to February 2001) meant that most of the turnover was voluntary rather than involuntary discharges or layoffs. For the purpose of this study, I eliminated employees who left the organization and later returned.

Age. Employees were asked to respond to one of eight categories for age. The categories included less than 20 years, 20-24, 25-29, 30-34, 35-39, 40-49, 50-59, and over 60. A score of 1-8 was given for each age category.

Weekend work. Employees who indicated that they worked any of the six shift options on the weekend were considered to be weekend workers. Weekend work was dummy coded with a score of 1 if the employee worked any weekends and 0 if they did not work any weekends.

Hours worked. Respondents were asked to indicate the minimum and maximum hours they worked. The mean of these two values was used to determine the average hours that employees worked each week. 
Number of children at home. Respondents were asked to indicate if they had none, one, two, three, four, or five or more children at home. A score of 0-5 was given for each category.

Analyses

I tested the path model with AMOS 4.0 (Arbuckle, 1999) (see Figure 1). Path analysis is a form of regression analysis that provides information about hypothesized relationships while taking into consideration the relationships among all other variables in the model. Path analysis examines several different regression equations simultaneously and uses partial regression analyses to determine path values and significance levels. Path analysis allows the researcher to test the overall fit of a hypothesized model and test the magnitude and significance of individual paths within the model that represent specific hypotheses. The model included three paths connecting the shift variable to commitment, satisfaction, and role stress, three paths connecting commitment, satisfaction, and role stress to intention to turnover and a path from intention to turnover to retention. Furthermore, based on a review of the literature (Tett \& Meyer, 1993) I expected that commitment, satisfaction, and role stress would be correlated due to shared antecedents. Finally, I included direct paths from the control variables to commitment, satisfaction, role stress, turnover intention, and retention. I tested the model with four different shift variables; mixed versus fixed, morning versus night, evening versus night, and morning versus evening.

I assessed the overall model fit using several fit indices. I examined the chisquare value for the proposed model. The chi-square test is based on sample size. In 
large samples, the chi-square statistic may be large, and therefore significant, even when the model is a good fit. Therefore, I also examined the comparative fit index (CFI) (Bentler, 1990). The CFI compares the hypothesized model to the independent model, where none of the variables are correlated. A CFI value above .95 is considered good model fit. The root mean square error of approximation (RMSEA) (Browne \& Cudeck, 1993) on the other hand, is an absolute fit index, which compares the proposed model to the sample data rather than an independent model. The value is derived from the variance of the residuals of the model. McDonald and Ho (2002) recommend that values between below .05 indicated good fit, and values between .05 and .08 can be considered "acceptable" model fit.

I tested the mediation hypotheses with the Sobel/MacKinnon method (MacKinnon, Lockwood, Hoffman, West, \& Sheets, 2002; Sobel, 1982). This method is based on the notion that mediation depends on the extent to which the predictor variable affects the mediator, and the extent to which the mediator predicts the outcome variable (MacKinnon \& Dwyer, 1993). The advantage to using this method is that it produces a $\mathrm{z}$-score, which can be evaluated for statistical significance. In the first step, I regressed the predictor variable on the proposed mediator (satisfaction, commitment or stress, or intention to turnover). In the second step, I regressed the proposed mediator on the outcome variable. For each regression analysis, I entered the control variables in the first step of the equation. The unstandardized regression coefficient and standard error from these analyses were then entered into an online calculator to calculate the value and significance of the mediation effect (Preacher, 
2003). This test determines a standard error for the product of the two regression coefficients. A z-score is obtained by dividing the estimated effect of the intervening variable by its standard error and comparing this value to a standard normal distribution (MacKinnon et al., 2002). I then compared the $\mathrm{z}$-score value to a cutoff value of $+/-1.96$ to determine if the values were significant at the $p<.05$ level. Significant values indicate the presence of mediation effects.

Finally, I tested the moderation hypotheses using hierarchical regression analysis. Before conducting the analysis, I centered each of the variables by subtracting the variable mean from each value. Centering variables reduces the effects of multicollinearity between the main effects and the interaction variable (Howell, 2002). I also computed scores for the interactions between the shift variables and supervisor support. I entered the data into the analysis in three steps. The first step included the control variables (number of children at home, hours worked, weekend work, and age). The second step included the centered variables for supervisor support and the shift variable. In the third step, I entered the interaction term. I examined the change in $\mathrm{R}^{2}$ at each step to determine if the variables added to the equation explained any additional variance in the outcome.

Prior to testing the hypotheses, I examined whether missing data was a concern. For the entire sample, only fourteen people had missing data for two or more variables. Further examination of the data revealed no significant patterns in the missing data. Therefore, all the data available were used in the analyses. However, for the analyses conducted in SPSS, the program uses only cases with complete data. 


\section{Results}

Descriptive Statistics

\section{Full Sample}

Demographic information for the entire sample can be found in Table 1. There were several notable demographic differences between individuals working fixed versus mixed shifts. Those working fixed shifts were older, had fewer children living at home, worked more hours per week, worked more weekend shifts, and were more likely to be full-time employees. However, since age, children at home, hours per week, and weekend work are control variables in the study, these differences should not affect the results.

Table 3 presents the correlations among the study variables for the mixed versus fixed analyses. Commitment and satisfaction $(r=.71)$, turnover intention and satisfaction $(r=-.63)$ turnover intention and organizational commitment $(r=-.51)$ were all highly correlated. The fact that these variables are so highly correlated is important to note when examining future analyses. Since commitment and satisfaction are being examined as joint predictors of turnover intention, it is possible that the paths will be affected by their common variance. The inclusion of both these variables as predictors in the model may cause one or both of the paths to be non-significant when there is a meaningful relationship. Furthermore, because commitment, satisfaction, role stress, and turnover intention were all self-report scales on the same questionnaire, there also is some concern about common method variance inflating these correlations. Therefore, I examined the model without each of these variables to 
ensure the results were not affected by the high correlations. The significance and direction of the paths were not affected by the removal of commitment, satisfaction, or stress from the model.

Although job satisfaction, organizational commitment, and role stress were significantly correlated with intention to turnover in the anticipated directions, commitment was negatively correlated with retention and stress was positively correlated with retention. These correlations indicate that individuals with low commitment and high stress remained with the organization longer than those with high commitment and low stress. I examined the correlation between retention and the individual items included in the commitment and role stress scales. The items in each of these scales were correlated with retention in the same direction as the entire scale, indicating that one specific item in the scale did not influence the direction of the correlation. Therefore, it appears that in this sample, commitment was negatively related to retention and stress was positively related to retention. This finding is inconsistent with most published research, which indicates that low commitment (Cotton \& Tuttle, 1986; Mathieu \& Zajac, 1990) and high stress (Hemingway \& Smith, 1999; Wright \& Cropanzano, 1998) are associated with decreased retention. Because of this inconsistency with prior research, caution should be taken when interpreting results associated with the organizational commitment and role stress scales.

The correlation between fixed versus mixed shifts and job satisfaction was not significant and close to zero. The correlations between mixed versus fixed shift work 
and organizational commitment, job satisfaction, role stress, turnover intention and retention were not in the anticipated directions. Fixed shift employees reported lower levels of commitment and higher levels of role stress and turnover intention than mixed shift employees. Furthermore, fixed shift employees remained with the organization longer than mixed shift employees. However an examination of the means suggests that these differences are not large, and the significance of the correlation is probably due to the large sample size.

Sub-sample for Shift Differences.

The subset of data for this set of analyses included 2,107 individuals who worked only one shift that was not an overlapping shift. Demographic information for the sub-sample can be found in Table 2. Due to the fact that all of these individuals worked at least some weekend shifts, weekend work was dropped as a control variable for these analyses. The data revealed patterns of demographic differences similar to the full sample. Means, standard deviations, and correlations can be found in Table 4. The sub-sample was further split into three different groups to examine night $(n=506)$ versus morning $(n=1,084)$ work, evening $(n=517)$ versus night $(n=506)$ work, and morning $(n=1,084)$ versus evening $(n=517)$ work. The direction and magnitude for the correlations were similar to those in the full sample.

Test of shift work differences retention levels

Due to the fact that there were several moderators in my model and many of the correlations were in directions contrary to my hypotheses, I conducted a series of $t$ - 
tests to determine if there were differences in employee retention between the different shift variables.

Mixed versus Fixed Shift

Results from the t-test indicated that fixed shift workers remained with the organization an average of two months longer than mixed shift workers, $t=8.21, p<$ .01 . Fixed shift workers stayed an average of $24.63(\mathrm{sd}=10.02)$ months after the original data collection, and mixed shift workers stayed an average of 22.35 (sd = 10.73) months.

Morning versus Night Shift

Results from the $\mathrm{t}$-test indicated that morning shift workers remained with the organization an average of two and a half months longer than night shift workers, $t=$ $4.64, p<.01$. Morning shift workers stayed an average of $26.21(\mathrm{sd}=8.9)$ months after the data collection, and night workers stayed an average of $23.84(\mathrm{sd}=10.64)$ months.

Evening versus Night Shift

Results from the t-text indicated that night shift workers remained with the organization an average of two and a half months longer than evening shift workers, $t$ $=-3.83 p<.01$. Night shift workers remained with the organization an average of $23.84(\mathrm{sd}=10.64)$ months after the data collection, while evening shift workers remained and average of $21.22(\mathrm{sd}=11.21)$ months. 
Morning versus Evening Shift

Results from the t-test indicated that morning shift workers remained with the organization an average of five months longer than evening shift workers, $\mathrm{t}=-9.61, p$ $<.01$. Morning shift workers stayed an average of $26.21(\mathrm{sd}=8.9)$ months after the original data collection, and evening shift workers stayed an average of 21.22 (sd = 11.21) months.

Tests of Hypotheses to Confirm Prior Research Turnover Intention as a Mediator

Hypotheses 1, 5, 10, and 15 were intended to confirm previous research. Hypothesis 1 predicted that that intention to turnover would be negatively related retention. Hypotheses 5, 10, and 15 predicted that that organizational commitment and job satisfaction and would be negatively related to turnover intention and role stress would be positively related to turnover intention. Results from the path model provided support for hypotheses $1,5,10$, and 15 for both the full sample and all of the sub-samples. The beta weights for these analyses can be found in Figures 2-5.

The results for the mediation analyses of intention to turnover for the full sample can be found in Table 5. Hypotheses 2a-c were intended to confirm previous research that intention to turnover mediates the relationship between organizational commitment, job satisfaction, and role stress, and retention. These hypotheses were all supported. Intention to turnover was a significant mediator of satisfaction $(\mathrm{z}=12.77, p$ $<.001)$, commitment $(\mathrm{z}=12.58, p<.001)$, and role stress $(\mathrm{z}=-11.49, p<.001)$ and retention. Commitment and satisfaction were positively related to intention to turnover 
and role stress was negatively related to turnover intention. Intention to turnover was negatively related to retention. Intention to turnover was also a significant mediator in each of the sub-samples. Results for the sub-sample analyses can be found in Tables 68.

All of the analyses intended to confirm prior research were consistent with prior literature (Cotton \& Tuttle, 1986; Griffeth et al., 2000; Tett \& Meyer, 1993; Wright \& Cropanzano, 1998). The relationships between commitment, satisfaction, stress, turnover intentions and retention were all significant and in the predicted directions. Even though the correlations between commitment and role stress and retention were not in the anticipated directions, the mediation analyses revealed that low commitment and high stress resulted in increased turnover intentions, which resulted in shorter retention. These findings make the unexpected correlations between commitment, role stress, and retention less of a concern. In the proposed model, commitment and role stress are not directly related to retention, but hypothesized to predict retention through turnover intentions.

Test of the overall model

Fixed versus Mixed Shift Schedules

The chi-square value for the proposed model was $135.09, p<.001$. However, due to the large sample size, a significant chi-square value was expected. The CFI value for the proposed model was .999 , above the cutoff of .95 for good fit ( $\mathrm{Hu} \&$ Bentler, 1999). The root mean square error of approximation (RMSEA) was .067, 
below the recommended cutoff of .08. Therefore, the model for the full sample testing mixed versus fixed shift schedules was found to have good overall fit.

The standardized path coefficients for the model can be found in Figure 2 . Hypotheses 3, 8, and 13 stated that individuals working fixed shift schedules would report higher levels of commitment (H3) and satisfaction (H8) and lower levels of role stress (H13) than those working mixed schedules. The paths between mixed versus fixed shift and satisfaction and role stress were not significant, indicating that hypotheses 8 and 13 were not supported. Contrary to hypothesis 3 , individuals working fixed shifts reported significantly lower levels of organizational commitment than those working mixed shifts. The magnitude of this path was quite small $(b=.03)$ but significant, indicating that small differences exist between mixed and fixed shift schedules.

Test of Specific Shift Differences

For the morning, night, and evening shifts, the model was tested three separate times, one for each combination of two shifts. Night workers were predicted to be worse off than either evening or morning workers. Relationships between morning and evening shifts were exploratory in nature, since there was not prior research to support a hypothesized relationship.

Morning versus night shifts. The chi-square value for the proposed model was $67.63, p<.001$. The CFI value for the proposed model was .99 , above the cutoff of .95 for good fit. The root mean square error of approximation (RMSEA) was .077. The 
standardized path coefficients for the model can be found in Figure 3. The overall model for morning versus night shift was found to have good model fit.

Hypotheses $4 a, 9 a$, and $14 a$ predicted that morning shift workers would report higher levels of commitment (H4a) and job satisfaction (H9a) and lower levels of role stress (H14a) than night workers. The coefficients for each of these paths were not significant, indicating that none of these hypotheses were supported.

Evening versus night shifts. The chi-square value for the proposed model was $51.6, p<.001$. The CFI value for the proposed model was .99 , above the cutoff of .95 for good fit. The root mean square error of approximation (RMSEA) was .067 . The standardized path coefficients for the model can be found in Figure 4. The overall model for the evening versus night shift was found to have good fit.

Hypotheses $4 b, 9 b$, and $14 b$ predicted that evening shift workers would report higher levels of commitment (H4b) and job satisfaction (H9b) and lower levels of role stress $(\mathrm{H} 14 \mathrm{~b})$ than night shift workers. The path coefficients indicated that hypotheses $4 \mathrm{~b}$ and $9 \mathrm{~b}$, but not $14 \mathrm{~b}$ were supported. As predicted, employees working the evening shift reported higher levels of commitment and job satisfaction than employees working the night shift. There were no significant differences between evening and night shift workers on role stress.

Morning versus evening shifts. The chi-square value for the proposed model was $85.17, p<.001$. The CFI value for the proposed model was .99 . The RMSEA was .087 , just above the cutoff of .08 for good model fit. Then standardized path 
coefficients for the model can be found in Figure 5. Therefore, the overall model for the morning versus evening shift was found to have acceptable fit.

Hypothesis 4c, 9c, and $14 \mathrm{c}$ were exploratory in nature, to examine if any significant differences existed between morning and evening shift workers. Path coefficients indicated that morning versus evening shift significantly predicted commitment (H4c) and job satisfaction (H9c), but not role stress (H14c). Employees working the evening shift reported higher levels of commitment and job satisfaction than employees working the morning shift.

Based on these results, it appears that job satisfaction and organizational commitment, but not role stress are influenced by the shifts people work. More specifically, evening workers report higher levels of job satisfaction and organizational commitment than day or night workers. There were no significant differences in stress between any of the shifts, suggesting that role overload is not influenced by the actual shift employees' work.

Commitment, Satisfaction, and Role Stress as Mediators

\section{Mixed versus Fixed Shift}

Results for the mediation hypotheses for the full sample can be found in Table 5. Hypotheses 6 predicted that organizational commitment would be a significant mediator of the effects of mixed versus fixed shift. Although commitment was a significant mediator, $(z=2.07, p<.05)$, the relationship between mixed versus fixed shift work and commitment was not in the anticipated direction. Individuals who worked more than one shift reported higher levels of commitment, and individuals 
with higher organizational commitment reported fewer intentions to leave the organization. Hypothesis 11 stated that job satisfaction mediates the relationship between fixed versus mixed shift work and tumover intention. The z-score from the Sobel/Mackinnon analysis was not significant, indicating that satisfaction was not a mediator. Hypothesis 16 predicted that role stress would mediate the relationship between mixed versus fixed shift work and turnover intention. The $z$-score for the Sobel/Mackinnon analysis was not significant, indicating that role stress was not a significant mediator.

\section{Tests of Individual Shift Differences}

Morning versus night shift. Hypotheses $7 \mathrm{a}, 12 \mathrm{a}$, and $17 \mathrm{a}$ predicted that commitment, satisfaction, and role stress would mediate the relationship between morning versus night shift and turnover intention. None of the z-scores from the Soble/Mackinnon analyses were significant, indicating that neither commitment, satisfaction, or role stress mediates the morning versus night shift-turnover intention relationship. Results for these analyses can be found in Table 6.

Evening versus night shift. Hypotheses $7 \mathrm{~b}, 12 \mathrm{~b}$, and $17 \mathrm{~b}$ predicted that commitment, satisfaction, and role stress would mediate the relationships between evening versus night work and turnover intention (Table 7). Hypotheses $7 \mathrm{~b}$ and $12 \mathrm{~b}$ were supported. Job satisfaction $(z=2.74, p<.01)$ and organizational commitment $(z$ $=4.80, p<.01)$ significantly mediated the relationship between evening versus night shift and turnover intention. Employees working the evening shift reported higher level of organizational commitment and job satisfaction than night workers, and were 
less likely to report intentions to leave the organization. Role stress was not a significant mediator.

Morning versus evening shift. Hypotheses $7 \mathrm{c}, 12 \mathrm{c}$, and $17 \mathrm{c}$ predicted that commitment, satisfaction, and role stress would mediate the relationships between morning versus evening shift and intention to turnover (Table 8). For the mediation of morning versus evening shift and turnover intention, job satisfaction $(\mathrm{z}=3.35, p<.01$ and organizational commitment $(z=6.54, p<.01)$, but not role stress significantly mediated the relationship. Employees working evening shifts reported higher levels of job satisfaction and organizational commitment than those working morning shifts. Test of Supervisor Support as a Moderator

Supervisor support was a proposed moderator between the shift variables and commitment, satisfaction and role stress. Table 9 represents the third step in the moderation analyses for the full sample. Tables $10-12$ represent the third step in the analyses for the shift variable (morning, evening, or night shift).

\section{Organizational Commitment}

Hypothesis 18 predicted that supervisor support would moderate the relationship between mixed versus fixed shift work and organizational commitment. The interaction between mixed versus fixed schedule and supervisor support was not significant. Hypotheses $19 \mathrm{a}-\mathrm{c}$ predicted that supervisor support would moderate the relationships between morning versus night work, evening versus night work, and morning versus evening work and organizational commitment. None of these hypotheses were significant. 
Job Satisfaction

Hypotheses 20 predicted that supervisor support would moderate the relationship between mixed versus fixed shift and job satisfaction. This hypothesis was not supported. Hypotheses 21 a-c predicted that supervisor support would moderate the relationships between morning versus night work, evening versus night work, and morning versus evening work and job satisfaction. Supervisor support was not a significant moderator of any of these relationships.

Role Stress

Hypotheses 22 predicted that supervisor support would moderate the relationship between mixed versus fixed shift and role stress. This hypothesis was not supported. Hypotheses 21a-c predicted that supervisor support would moderate the relationships between morning versus night work, evening versus night work, and morning versus evening work and role stress. Supervisor support was a significant moderator of the day versus evening shift-role stress relationship, but not the other two shift variables. The relationship between morning versus evening shift work and role stress was stronger for employees who perceived high levels of supervisor support (Figure 7). Evening shift workers who perceived high levels of supervisor support reported the lowest levels of role stress. This finding supports prior research indicating the social support buffers the effects of demanding job characteristics on employee stress (Johnson \& Hall, 1988; Karasek \& Theorell, 1990). 


\section{Discussion}

The purposes of the present study were to investigate the relationships between several shift work variables and employee retention, and to examine three potential mechanisms that may link shift work to retention. Some of the results of the study confirmed prior research, some conflicted with prior research, and some provided new insights into the effects of shift work on both individuals and organizations. In this discussion I will review and provide possible explanations for the findings of my study.

Perhaps the most interesting findings of my study concerned the effects of different shift schedules on organizational outcomes. An examination of mean differences revealed that fixed shift workers have longer retention than mixed shift workers, and that morning shift workers had the longest retention, followed by night workers and evening workers respectively. However, when examined through the process model, different results emerged. The finding that mixed shift workers reported higher levels of organizational commitment than fixed shift workers contradicts previous research indicating that fixed shifts are more desirable (Jamal, 1981; Pattanayak, 2002). In addition, evening shift workers reported higher levels of commitment and satisfaction than night workers and day workers. High commitment and satisfaction were related to weaker turnover intentions, which in turn were related to longer retention. In this study, role overload was not related to shift variables. Finally, supervisor support did not appear to influence the effects of different shift schedules on commitment, satisfaction, or role stress. The results of this study 
emphasize the fact that there are differences between the actual retention means of different shifts, and the process that employees go through when making turnover decisions.

Findings to Support Prior Research

Commitment, satisfaction, and role stress were all significantly related to turnover intention, confirming an established body of research (Eby et al., 1999; Mathieu \& Zajac, 1990; Tett \& Meyer, 1993; Wright \& Cropanzano, 1998). Intention to turnover was also a significant mediator of the relationships between commitment, satisfaction, and role stress, and retention. Although the bivariate correlations between commitment and retention and role stress and retention were in directions that contradict previous research, when examined through intentions to turnover, the relationships were in the expected directions. That is, higher organizational commitment and lower role stress were associated with weaker intentions to leave, and weaker intentions to leave were associated with longer retention.

\section{Fixed versus Mixed Shift Schedules}

Employees working fixed or mixed shift schedules did not differ in their reported levels of job satisfaction or role stress, nor did either of these variables mediate the relationships between mixed versus fixed shift work and turnover intention. Contrary to previous research (Jamal \& Baba, 1992) mixed shift workers reported higher levels of organizational commitment than fixed shift workers. These results suggest several interesting implications concerning the nature of different types of work schedules on organizational outcomes. 
The finding that mixed shift work is related to commitment and not satisfaction or role stress suggests that employees may attribute the pattern of shifts they work (mixed versus fixed shift schedule) to organizational factors rather than characteristics of their job. The methods used to determine the pattern of shifts that employees work are determined by the organization. An organization may choose to assign employees to relatively fixed schedules, or use mixed schedules that fit their shifting work demands. The finding that mixed shift work led to higher levels of organizational commitment than fixed shift work contradicts prior research emphasizing the benefits to working a fixed schedule. This finding suggests that more information may be needed before researchers are able to draw conclusions about the effects of work schedule on organizational outcomes. There may be other variables, such as control over schedule that may influence the relationship between mixed versus fixed shift work and organizational variables. Potential reasons why mixed shift workers report higher levels of commitment include group differences and the type of mixed shift worked.

One interesting finding in my study is that there were demographic differences between individuals who work fixed and mixed shift schedules. Employees working mixed shift schedules were younger, less likely to be married, and more likely to be in school and part-time workers. Mixed shift workers also had been with the organization a shorter period of time than the fixed shift workers. These individual differences may be related to the way employees react to different work schedules, as well as possibly influencing differences in reported commitment levels. In terms of tenure, it may also 
be that organizational commitment decreases over time for these employees. Future research may want to explore the moderating effects of employee tenure on the shift work-commitment relationship.

There are several ways that these group differences could lead to different commitment levels. Employees who are younger, single, and in school have different types of non-work demands than their older and married counterparts. For example, many young students have non-work responsibilities that include schoolwork and other individual needs (e.g. hanging out with friends). On the other hand, the fixed shift workers' non-work responsibilities may be much more focused on taking care of other people (e.g. children or spouse). Students may be happy working mixed schedules because it allows them to coordinate their work with class schedules. Furthermore, students can usually set their own schedules for studying and have some flexibility in the class times they choose. For these individuals, working around different work schedules may be easier. On the other hand, people with families have many responsibilities that are related to other people. For example, arranging childcare may be more difficult than finding a time to study for an exam. For these individuals, working any type of non-standard schedule may be difficult, regardless of whether it is fixed or mixed. This may be especially true in the current sample, because the shifts start early, end late, or go through the night. Until more research is done, it is difficult to determine whether it is the characteristics of these individuals, or their schedules that is causing differences in organizational commitment. 
In the present study, I was not able to differentiate between mixed shift workers who worked regular rotating schedules and those whose schedules changed every week. It may be that certain employees are on a fixed rotating schedule. In this type of schedule, an employee works different shifts throughout the week, but the schedule is the same from week to week. Although employees still change shift times in this type of schedule, they at least know when they will be working each week. A randomly mixed schedule may be stressful because employees cannot plan ahead. Although research indicates that a mixed schedule can negatively influence circadian adjustment (Knauth, 1996), it may be that certain individuals choose to work this type of schedule. For example, employees who attend school three days a week may prefer a weekly schedule of two morning shifts and three evening shifts to fit their class schedule. Additionally, I was unable to assess whether individuals in this sample worked the same number of hours from week to week. It may be that the type of schedule that is most negatively evaluated by employees is one in which the schedule is unpredictable and number of hours changes from week to week.

\section{Shift Differences}

The proposed model was tested with three different subgroups of the sample, comparing evening and night shifts, morning and night shifts, and morning and evening shifts. This study contributes to the current body of shift work research because few studies have compared these three shifts. An examination of the group means of retention indicated that morning shift workers remained with the organization the longest, followed by night workers and evening workers respectively. 
As with the fixed versus mixed shift schedules, it appears that the mean differences in retention and the process model for explaining employee retention yield different results, suggesting there may be other factors influencing these relationships.

The findings that evening shift workers report higher levels of commitment and satisfaction than night workers supports previous research concerning the negative effects of night work. Although there has not been prior research on these specific outcomes, night work has been associated with occupational violence (Salminen, 1998), loneliness (Bohle \& Tilley, 1998), and poor sleep quality (Bourdouxhe et al., 1999). Night shift and morning shift workers did not significantly differ on commitment, satisfaction, or role stress, which contradicts research highlighting the negative effects of night work. However there may be differences between the outcomes evaluated in this study and the mostly health-related outcomes examined in previous research. These results suggest that other variables influencing levels of commitment, satisfaction, and stress may need to be examined along with the shifts employees work. Some potential variables to include in future models include shift schedule preferences, employee tenure, and work status.

The finding that shift worked (morning, evening, or night shift) was related to both organizational commitment and job satisfaction suggests that employees view the shift they work as both a characteristic of the job and an organizational policy. The need for around the clock work may be understood by employees working in stores that operated on a twenty-four hour schedule. Therefore, individuals who are unhappy with their schedules may decide they do not like their jobs, but understand that if they 
worked in similar jobs at another organization they would have a similar schedule. However, employees also seem to feel that the organization has some influence on the shifts they work. It may be that although individuals realize the job requires working during non-standard hours, they may still be unhappy with the organization for scheduling them to work on these shifts.

Individuals who worked the night shift did not differ from those who worked the morning shift on reported levels of organizational commitment, job satisfaction, or role stress. The lack of findings concerning commitment, satisfaction, and stress is surprising considering the amount of research that suggests the negative effects of night work on employee well-being (Bourdouxhe et al., 1999; Costa, 1996). However, most of this research focuses on individual health outcomes as opposed to organizational outcomes. Further, night work has traditionally been studied in terms of fixed versus rotating night shifts or compared to a standard (9-5) day shift (Barton, 1994; Parkes, 1999). In the present study, the morning shift begins at 6:00 a.m. It may be that employees working this shift have to get up so early that they experience similar levels of fatigue and sleepiness as individuals who work at night. Another explanation might be that certain individuals choose to work the night shift. Almost twice as many people in my sample work the morning shift as the evening or night shift. Since more employees are needed at this time, it may be that more people are working this shift but would prefer to work either evening or night. In terms of demographic differences, night and morning shift workers were more similar than evening workers. Therefore, it may be that these individuals are reporting lower levels 
of commitment and satisfaction than evening workers because of demographic differences rather than shift work.

It was also interesting to note that employees working the evening shift were more committed and satisfied than morning workers. In terms of literature, I do not know of any study that has compared these two shifts. Employees may prefer the evening shift because they start work later in the day, but do not work too late into the evening. This type of schedule may help employees manage their work and non-work lives. For example, employees could use the time before their shift starts at 2:00 to take classes, watch their children, or attend another job. Finally, since this shift ends at 10:00 p.m., the sleep related effects of shift work should be less relevant to employees working this shift.

The demographic differences between the different shift groups provide one possible explanation for why evening shift workers reported higher levels of job satisfaction and affective commitment than morning and night workers. Twenty three percent of the individuals working the evening shifts were currently in school, where only ten percent of employees working the morning or night shift were students. In addition, only forty percent of employees working the evening shift had children, compared to fifty-one percent working the morning shift and fifty-four percent working the night shift. Additionally, employees working the evening shift were younger and more likely to be part-time workers than those working the morning or night shift. It may be that these demographic differences result in two different groups of people, who respond to certain work schedules or interpret actions of their 
organizations in distinct ways. It is difficult to determine whether it is the work shifts, the individual characteristics, or an interaction between the two that contribute to the reported differences in organizational commitment and job satisfaction. Studies examining demographic differences in schedule preferences, and commitment and satisfaction levels are needed to understand these complex relationships.

\section{Shift Preference}

One important influence that I was not able to capture in this study was individual schedule preference. Holtom et al. (2002) found that employees who work on their preferred schedules are more committed and are less likely to leave the organization. In another study conducted in Israel, met schedule preference was positively related to commitment but not intentions to leave (Krausz et al., 2000). Zedeck et al. (1983) found that individuals who did not want to change their work schedules reported higher levels of both job and life satisfaction. This research suggests that control over work schedule may be an important variable to examine in the study of shift work.

In terms of social exchange theory, employees may view the ability to manage their schedules as an inducement from the organization, and therefore reciprocate with increased levels of commitment. In addition, employees may see schedule control as a positive job characteristic, which leads them to feel more satisfied with their job. Finally, the ability to have input into one's work schedule may reduce role stress. Employees may benefit from working mixed schedules or evening shifts if they choose to do so in order to relieve scheduling conflicts in other areas of their lives. 
Individuals may choose to work a mixed schedule or evening shifts for a variety of reasons. As noted above, employees working these schedules were more likely to be younger, be students, and not have children. It may be that these individuals prefer to work mixed schedules or evening shifts because these schedules are more compatible with another aspect of their lives, such as another job or a class schedule. Individuals may also choose to work these schedules if they are more inclined towards "morningness," which is characterized by a preference for activities early in the morning or late at night (C. S. Smith et al., 2002). It may be that individuals who work better at night prefer the evening shift because they can sleep in but do not have to work all night long. Future research should explore individual differences in morning-evening orientation to assess its effects on the relationships between work schedules and organizational variables.

Information gained from the union suggests that employees in the present sample are granted schedule preferences based on tenure. Investigation of the sample revealed that employees working mixed shifts had been with the organization an average of 75 months, while fixed shift workers had been with the organization for 106 months on average. Similarly, employees working evening shifts had been with the organization an average of 51.5 months, as opposed to 122 months for morning workers and 78 months for night workers. It is important to note that there was great variability within these groups as to the length of tenure. However, it appears that on average, employees who report the highest levels of commitment and satisfaction have been with the organization the least amount of time. Furthermore, since schedule 
preference is based on tenure in this organization, it seems as though preference for mixed or evening work may not be the cause for the high reported levels of commitment and satisfaction. An interesting avenue for future research would be to investigate tenure as a possible moderator of relationships between shift work, organizational commitment, and job satisfaction.

\section{Supervisor Support}

Results indicated that supervisor support does not moderate the relationship between fixed versus mixed shift work and commitment, satisfaction, or role stress. However, it is possible that supervisor support may be influential in another part of the model. For example, the buffering effects of supervisor support may be more salient in the relationships between commitment, satisfaction, and role stress and turnover intention. Perhaps supervisor support is more influential after an employee has developed feelings of low commitment and job satisfaction or high role stress. Supervisor support may influence employees' likelihood of thinking about leaving by helping them deal with these negative feelings. Future research should further explore some of these alternative models of the influence of perceived supervisor support on shift work.

Supervisor support only moderated the relationships between individual shifts and commitment, satisfaction, and role stress in one case. The relationship between morning versus evening work and role stress was moderated by supervisor support. Employees who worked evening shifts and perceived high levels of supervisor support 
reported the lowest levels of turnover intention. However, overall, supervisor support did not appear to influence the impact of different shifts on organizational variables.

The finding that supervisor support does not influence reactions to shift work may indicate that supervisors are not doing enough to help employees manage potential negative effects associated with shift work. Previous research suggests that supervisors can buffer the negative effects of organizational stressors, and it follows that supervisors should be able to influence reactions to work schedules. Perhaps the organization should consider encouraging supervisors to communicate with their employees regarding work schedules. Since it appears that employees in this sample do not necessarily prefer the "expected" schedule types, supervisors may be able to help facilitate adjustment of different schedules.

Summary of Findings

There are several interesting themes that emerge from the different shift work variables that were examined. Role stress did not appear to be related to shift work in any of the analyses conducted, suggesting that role stress may not be a relevant outcome of shift work differences. It may be that a different type of stress, such as role conflict is more relevant in shift work. In addition, there was an interesting pattern of demographic differences in the individuals who reported more positive levels of organizational commitment and job satisfaction. Finally, supervisor support did not appear to affect employee responses to shift work.

The finding that commitment but not satisfaction was related to fixed versus mixed schedules suggests that employees attribute shift pattern (mixed or fixed) to 
organizational policies rather than a characteristic of the job itself. Employees working mixed schedules reported higher levels of commitment but there were no significant differences in job satisfaction. Employees working different types of schedules may be equally satisfied or dissatisfied with their jobs, regardless of the type of schedule they work. This suggests that these employees may not see fixed versus mixed schedules as being a job characteristic, but rather see these schedule patterns as a organizational policy. Both commitment and satisfaction were linked to shift worked (morning, evening, or night). These findings suggest that employees acknowledge that working different shifts is a necessary part of retail work. The difference between these two aspects of schedule variables may suggest that employees attribute 24-hour work to the nature of a job, but feel that the organization has some control over the way it schedules employees. This may be especially salient if employees work schedules in which their hours fluctuate. These results indicate that organizations should consider their policies on determining shift patterns. For example, allowing employees input into their schedules may increase positive feelings towards the organization.

Employees who are unhappy with their schedule and feel that the organization is responsible may retaliate against the organization in the form of counterproductive work behaviors, withdrawal behaviors, or unsafe behaviors. Social exchange theory states that individuals will assess inducements provided by their organization and respond with differing levels of commitment. If employees do not feel valued and respected by their organization, they will be less likely to respond with positive behavior. Indeed, in my study employees who reported lower commitment to the 
organization also reported higher turnover intentions. Organizations may want to consider this when presenting schedule policies to their employees. This may be as simple as explaining to employees why a certain scheduling pattern is used. However where organizations can really make a difference is in the design of work schedules. Organizational decision makers should think about issues such as circadian disturbance, fatigue, and employee preferences for schedule when designing schedule policies.

The lack of findings regarding role stress may be because the nature of these retail jobs is not very demanding. Aside from overtime, employees do not work outside of the hours they are scheduled. This may be unlike other jobs, where employees may bring their work home with them. Perhaps role overload applies more to that type of job than to retail jobs. In fact, it is possible that in some of these jobs, employees may be experiencing a lack of challenge, rather than feeling overloaded. This may be true especially during night shifts, where the stores are less likely to be busy. Employees also may be experiencing different types of stress as a result of their work schedules, such as role conflict or burnout. Future researchers may want to consider these stress variables as potential outcomes of different shift schedules or a combination of shift schedule and control over schedule.

Employees who reported higher levels of job satisfaction and organizational commitment were more likely to be part time, single, and students, and had shorter tenure than employees reporting low levels of satisfaction and commitment. In addition to work schedules, these group differences may contribute to the varying 
levels of organizational commitment and satisfaction. For example, research has found that relationships between employee commitment and organizational outcomes decrease over time (Cohen, 1993; Wright \& Bonett, 2002). It is possible that employees working a fixed shift may have reported lower levels of commitment because they have been with the organization for longer and have become disillusioned. Additionally, part time workers and students who were unhappy with one of these jobs may have already left. Employees who are younger and do not rely on the job to support a family may have more flexibility to leave the organization if they are unhappy. Therefore, the employees with these characteristics that are left are those with more positive attitudes.

Another interesting trend is that supervisor support does not appear to influence the relationship between employee schedule and commitment, satisfaction, or stress. Because schedules are based on tenure, supervisors probably do not influence when people work. However, even if they do not set schedules, supervisors appear to be able to buffer some of the negative outcomes of working an undesirable shift. This finding suggests that organization can benefit from training supervisors to help employees deal with difficult schedules. 


\section{Limitations and Suggestions for Future Research}

The unexpected results of this study suggest many questions and avenues for future research. Previous research outlined in this paper suggests that mixed shifts and night work are less ideal for employees. However results of this study indicate that the relationships between shift work and commitment, satisfaction, and stress may be more complicated and may involve more variables than were included in this study. Additionally, results suggest differences between the mean retention times of the shift groups and the results of the process model. Nonetheless, findings from this study present many new questions to be addressed in future research.

In this study, both mixed shift and evening shift workers were more likely to be part-time workers, who were single, in school, and had shorter organizational tenure. It is possible then, that due to demographic differences, these two groups of employees represent distinct groups, suggesting that either work schedule or demographic differences could be responsible for differences in commitment. Additionally, single, part-time, student workers who were unhappy in their jobs may have already left the organization. Further research should explore group differences and look at retention differences in relation to these demographic variables to gain a more accurate understanding of how shift work influences commitment, satisfaction, role stress, and retention.

One limitation of this study is the lack of a measure for schedule or shift preference. Data concerning the extent to which people have input into their schedule could provide further insight into the differences in levels of commitment, job 
satisfaction, and stress. Past research has shown than individuals who work their preferred schedule report higher levels of organizational commitment and job satisfaction (Holtom et al., 2002). However, based on the influence of tenure on work schedule preference in this study, it appears that preference may not have influenced commitment, satisfaction, and stress levels. Future research should explicitly examine shift preference to determine its effects on the relationships between shift work and organizational variables.

Although satisfaction and commitment were more influential than role stress in linking shift work to retention in this study, stress should not necessarily be discounted as a potential outcome of work schedules. The present study examined role overload as a potential stressor for employees. However there may be other types of stressors that influence shift employees, and that are more directly related to retention. Presently, there are only a handful of studies that examine the effects of shift work on stress. Furthermore, at least two of these studies focus on the stress-related cumulative effects of shift work over time (Kandolin, 1993; Olsson et al., 1990). It may be that shift work creates other types of stressors for employees to cope with. For example, mixed shift employees may experience role conflicts rather than role overload. For example, the job may not be very demanding, but arranging family responsibilities around a mixed work schedule may be. Future research is needed to explore different stressors that shift work may create, as well as the outcomes of these stressors.

It is also important to acknowledge the limitations of path analysis. One of the assumptions of path analysis is that all the proper variables are included in the model, 
with the appropriate relationships specified. Although each hypothesis was developed based on theory and research, there are still many unanswered questions in the shift work literature, and some debate concerning the nature of the relationships of the variables in the model. Future research is needed to develop a more complete theoretical model of the effects of shift work on organizational outcomes. This model would include other variables that influence organizational commitment, job satisfaction, role stress, turnover intention, and employee retention. Some examples of other variables to include in the model would be employee tenure, demographic differences (e.g. work status, school or marital status), shift preference, and other outcomes (e.g. absenteeism, employee performance, role conflict, or burnout). Another assumption of path analysis is that all of the variables are measured without error. While it is generally accepted that this is unrealistic in social sciences research, there may be cause for concern in my data, because the correlations between organizational commitment and role stress and retention were in directions that contradicted previous research. Future research should included different measures of these variables to determine if the relationships vary with the measurement scale. An additional problem associated with measurement in this study is the fact that I was not able to capture previous tenure when calculating retention. The retention variable in this study was calculated from the initial data collection through the following 31 months. Therefore, an employee who had worked a month before the data collection received the same retention score as an employee who had worked twenty years before the data collection. Future researchers should consider including tenure in the model 
as a possible moderator. Finally, future research may want to explore different ways of capturing more detail about employees work schedules. For example, more research is needed to pull apart the different types of mixed schedules, to examine differences between fixed rotating and random mixed schedules.

Although this study investigated a model, it was not intended to fully explain the effects of shift work on organizational retention. Rather the goal of this study was to examine potential mechanisms linking shift work to retention. Future research should develop a complete model to explain the relationships between shift work and retention. One key variable in a complete model would be the effects of perceived employment mobility on retention. Many retention models include employment mobility as a key factor in an employee's decision to contemplate and actually leave an organization (Hom \& Griffeth, 1991; Lee \& Mitchell, 1994). Furthermore, there may be other relevant organizational outcomes, such as job performance or absenteeism that are influenced by shift work. More research concerning shift work is needed to develop empirical support for the development of such a model.

Since this study was conducted on a large sample of retail workers, readers should be hesitant to apply these findings to individuals in other occupations. Although it may be true that mixed shift workers report higher levels of organizational commitment than fixed shift workers, and evening shift workers report higher levels of organizational commitment and job satisfaction than morning or night workers, more research is needed to explore these relationships on other employee samples. Furthermore, knowledge of the organization's policies and procedures regarding work 
schedules, including the extent employees work a preferred schedule is essential to improving understanding of the relationship between shift work and organizational variables. Finally, shift work may be confounded with other variables, such as demographic differences or employee tenure. Future research should explore these differences by testing models on different demographic groups to determine if the effects are consistent. 


\section{Conclusions}

Overall, results from this study emphasize the need for more research concerning the effects of work schedules on organizational outcomes. The fact that many of the findings contradict prior research suggests that the relationships between work schedules and turnover are complex and may involve variables not included in this study. It appears that demographically distinct groups of people work different shift schedules. What is not clear is whether these individuals are choosing to work these schedules and how their choices influence the effects of schedules on organizational outcomes.

An interesting thing to note in this study is the difference between the mean comparisons of the different shift variables and the results of the process model. The fact that fixed shift workers stayed with the organization longer than mixed shift workers but also reported lower levels of organizational commitment suggests that the relationship between shift work and employee retention is a complicated process. Most likely, there are other variables that contribute to employees' affective reactions to their organization, as well as their decision to remain with or leave the organization. Perhaps future research should focus on more proximal outcomes of shift work, such as employee tardiness and absenteeism or accidents and injuries.

However it does appear that certain work schedule variables differentially affect job satisfaction and organizational commitment, and that these variables are related to employee retention. These findings support the notion that individuals experience certain cognitions before making an ultimate decision to leave the 
organization. Therefore, it would seem as though organizations could influence employees' affective responses to their jobs before they actually leave the organization. Presently, supervisors do not appear to be influencing employee reactions to work schedules, but there may be opportunities for supervisors to have a greater impact on these reactions. For example, if employees know that night workers are less likely to be committed than evening workers, supervisors may be able to provide additional support or benefits to increase employee commitment and retention. Continued research can help employers to understand these relationships and develop policies to avoid turnover and improve employee well being. 
Table 1

Demographic Data for Full Sample

\begin{tabular}{|c|c|c|c|}
\hline & $\begin{array}{l}\text { Total Sample } \\
(\mathrm{n}=5,789)\end{array}$ & $\begin{array}{l}\text { Fixed Shift } \\
(\mathrm{n}=3,511)\end{array}$ & $\begin{array}{l}\text { Mixed Shift } \\
(\mathrm{n}=2,278)\end{array}$ \\
\hline \multicolumn{4}{|l|}{ Gender } \\
\hline Male & $31.6 \%$ & $33.5 \%$ & $28.7 \%$ \\
\hline Female & $68.4 \%$ & $66.5 \%$ & $71.3 \%$ \\
\hline \multicolumn{4}{|l|}{ Age } \\
\hline Under 20 & $8.7 \%$ & $5.4 \%$ & $13.9 \%$ \\
\hline $21-29$ & $19.8 \%$ & $16.9 \%$ & $24.3 \%$ \\
\hline $30-39$ & $24.5 \%$ & $26.1 \%$ & $20.8 \%$ \\
\hline $40-49$ & $25.8 \%$ & $27.6 \%$ & $23.0 \%$ \\
\hline $50-59$ & $15.1 \%$ & $16.8 \%$ & $12.4 \%$ \\
\hline 60 and older & $6.0 \%$ & $7.3 \%$ & $4.1 \%$ \\
\hline \multicolumn{4}{|l|}{ Marital Status } \\
\hline Married & $54.2 \%$ & $57.5 \%$ & $49.2 \%$ \\
\hline Single & $44.2 \%$ & $40.8 \%$ & $49.4 \%$ \\
\hline \multicolumn{4}{|l|}{ Work Status } \\
\hline Full-time & $51.6 \%$ & $60.8 \%$ & $37.4 \%$ \\
\hline Part-time & $48.4 \%$ & $39.2 \%$ & $62.6 \%$ \\
\hline \multicolumn{4}{|l|}{ Weekend Work } \\
\hline Works weekends & $83.5 \%$ & $75.9 \%$ & $95.1 \%$ \\
\hline Does not work weekends & $15.8 \%$ & $24.1 \%$ & $3.1 \%$ \\
\hline
\end{tabular}


Currently in School

No

$82.7 \%$

$87.8 \%$

$74.9 \%$

High School

$4.9 \%$

$2.9 \%$

$8.1 \%$

Vocational or Technical

$.9 \%$

$0.8 \%$

$1.0 \%$

School

College

$10.3 \%$

$7.6 \%$

$14.6 \%$

Graduate School

$.8 \%$

$.7 \%$

$.8 \%$

Number of Children at

Home

None

$54.1 \%$

$52.7 \%$

$56.1 \%$

One

$17.3 \%$

$18.5 \%$

$15.4 \%$

Two

$17.9 \%$

$18.1 \%$

$17.5 \%$

Three

$7.1 \%$

$7.2 \%$

$7.1 \%$

Four

$2.2 \%$

$2.0 \%$

$2.4 \%$

Five or More

$.9 \%$

$1.0 \%$

$.7 \%$

* Differences between sum of values and $100 \%$ represents missing data 
Table 2

Demographic Data for Sub-sample of Fixed Shift Employees

\begin{tabular}{lcccc}
\hline & $\begin{array}{c}\text { Total } \\
(\mathrm{n}=2,017)\end{array}$ & $\begin{array}{c}\text { Morning Shift } \\
(\mathrm{n}=1,084)\end{array}$ & $\begin{array}{c}\text { Evening Shift } \\
(\mathrm{n}=517)\end{array}$ & $\begin{array}{c}\text { Night Shift } \\
(\mathrm{n}=506)\end{array}$ \\
\hline Gender & & & & \\
Male & $33.3 \%$ & $23.5 \%$ & $38.1 \%$ & $49.4 \%$ \\
Female & $66.7 \%$ & $76.5 \%$ & $61.9 \%$ & $50.6 \%$ \\
\hline Age & & & & \\
Under 20 & $4.6 \%$ & $1.8 \%$ & $12.6 \%$ & $2.6 \%$ \\
$21-29$ & $18.5 \%$ & $14.1 \%$ & $24.8 \%$ & $21.8 \%$ \\
$30-39$ & $18.3 \%$ & $26.2 \%$ & $22.0 \%$ & $34.8 \%$ \\
$40-49$ & $27.1 \%$ & $31.5 \%$ & $18.4 \%$ & $26.5 \%$ \\
$50-59$ & $16.1 \%$ & $18.4 \%$ & $15.1 \%$ & $12.5 \%$ \\
60 and older & $6.4 \%$ & $8 \%$ & $7.2 \%$ & $2 \%$ \\
\hline
\end{tabular}

Marital Status

Married

$55.3 \%$

$61 \%$

$40 \%$

$58.7 \%$

Single

$42.9 \%$

$37.4 \%$

$57.8 \%$

$39.5 \%$

Work Status

Full-time

$59.2 \%$

$61.0 \%$

$41.4 \%$

$73.0 \%$

Part-time

$40.8 \%$

$39.0 \%$

$58.6 \%$

$26.0 \%$

Currently in School

No

$87.5 \%$

$90.8 \%$

$77.8 \%$

$90.7 \%$ 


\begin{tabular}{lcccc} 
High School & $2.6 \%$ & $1.1 \%$ & $7 \%$ & $1.2 \%$ \\
$\begin{array}{l}\text { Vocational or } \\
\begin{array}{l}\text { Technical School } \\
\text { College }\end{array}\end{array}$ & $.8 \%$ & $.05 \%$ & $1.0 \%$ & $1.4 \%$ \\
Graduate School & $8.1 \%$ & $6.8 \%$ & $13.2 \%$ & $5.7 \%$ \\
\hline $\begin{array}{l}\text { Number of Children } \\
\text { at Home }\end{array}$ & $0.6 \%$ & $1.0 \%$ & $0.8 \%$ \\
$\begin{array}{l}\text { None } \\
\text { One }\end{array}$ & $54.4 \%$ & $48.8 \%$ & $60.9 \%$ & $46.2 \%$ \\
Two & $18.8 \%$ & $19.7 \%$ & $16.4 \%$ & $19.2 \%$ \\
Three & $18.7 \%$ & $20.5 \%$ & $13.5 \%$ & $20.4 \%$ \\
Four & $7.6 \%$ & $7.2 \%$ & $5.6 \%$ & $10.5 \%$ \\
Five or More & $2.2 \%$ & $2.3 \%$ & $1.7 \%$ & $2.4 \%$ \\
\hline * Differences between sum of values and 100\% represents missing data & & & \\
\hline
\end{tabular}




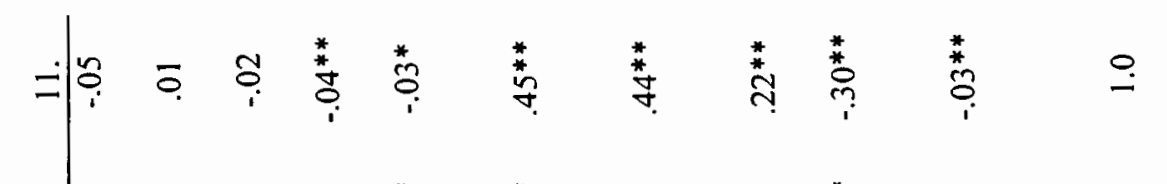

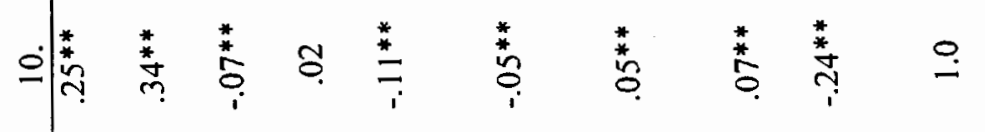

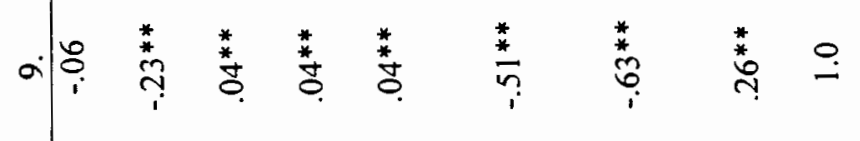

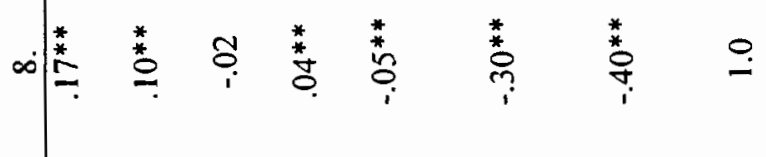

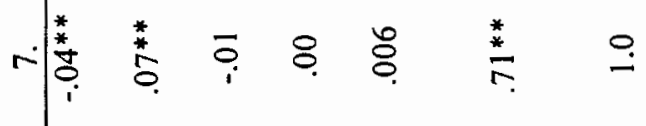

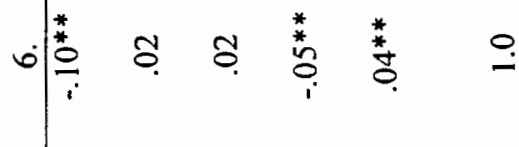

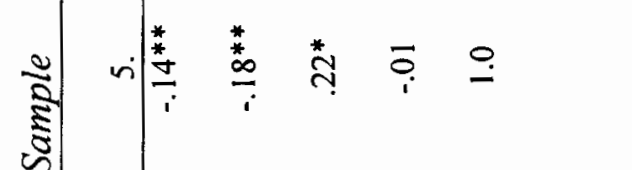

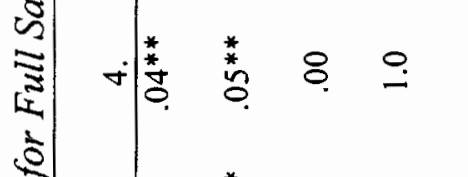

$$
\begin{aligned}
& \text { 犃 } \\
& \text { 党 } \\
& \text { 氕 }
\end{aligned}
$$

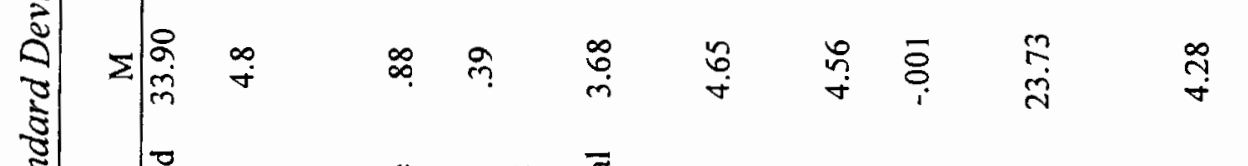




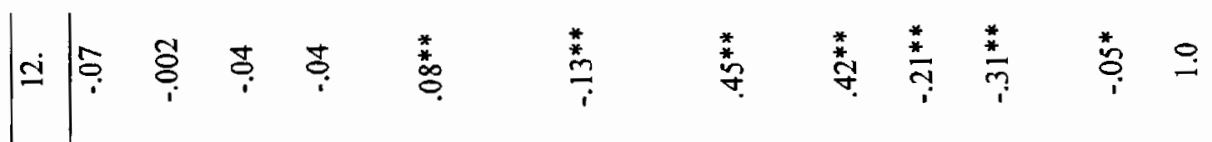

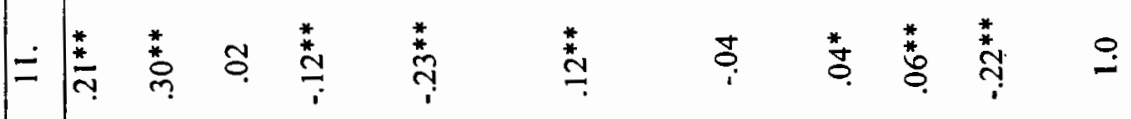

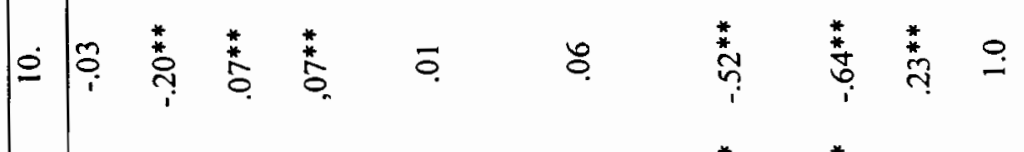

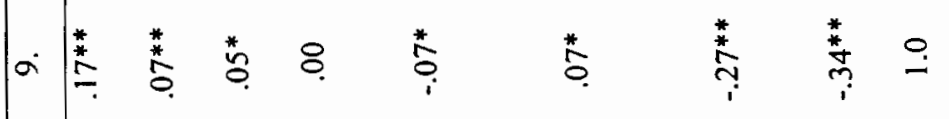

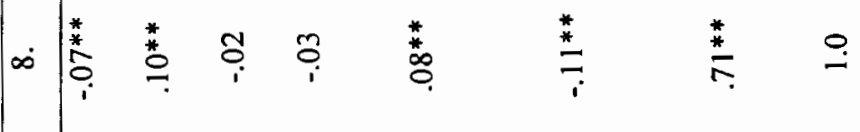

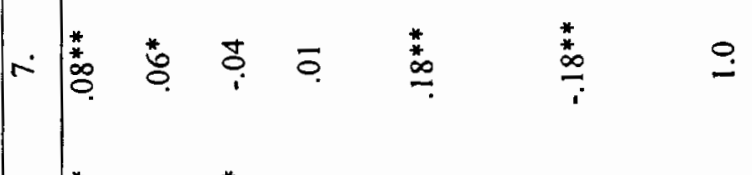

.

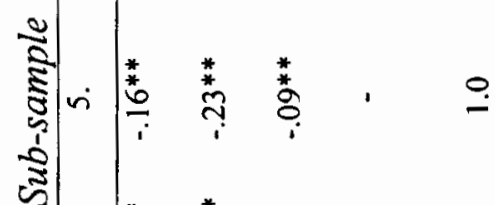

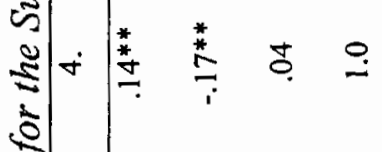

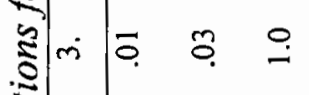

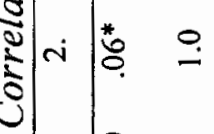

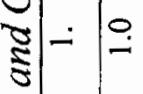

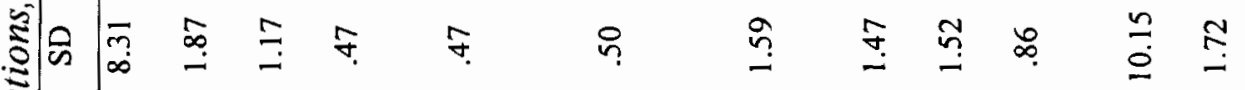

๖े๊

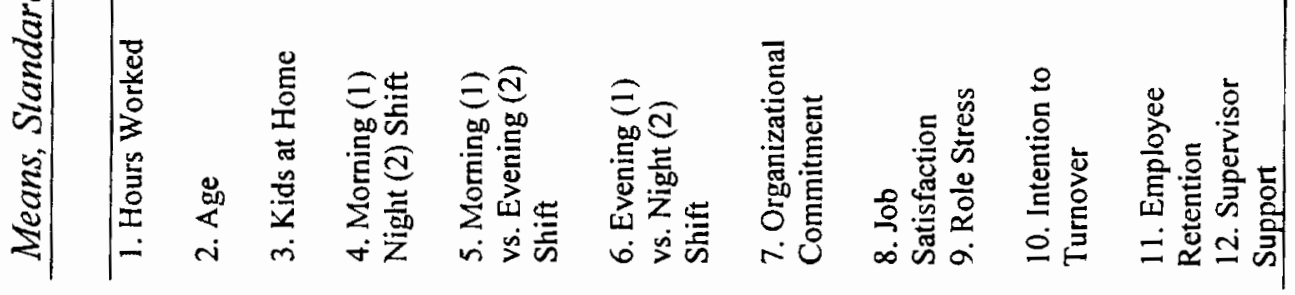


Table 5

Mediation Analyses for Fixed versus Mixed Shift

\begin{tabular}{|c|c|c|c|c|c|}
\hline & B & $\mathrm{se}$ & B & se & $z$-score \\
\hline $\begin{array}{l}\text { Fixed (0) vs. Mixed (1) Shift to } \\
\text { Satisfaction }\end{array}$ & -.05 & .04 & & & \\
\hline Satisfaction to Turnover Intention & & & -.36 & .01 & 125 \\
\hline $\begin{array}{l}\text { Fixed (0) vs. Mixed (1) Shift to } \\
\text { Commitment }\end{array}$ & .09 & .05 & & & \\
\hline Commitment to Turnover Intention & & & -.28 & .01 & $2.07^{*}$ \\
\hline $\begin{array}{l}\text { Fixed (0) vs. Mixed (1) Shift to Role } \\
\text { Stress }\end{array}$ & .04 & .04 & & & \\
\hline Stress to Turnover Intention & & & .17 & .01 & .92 \\
\hline $\begin{array}{l}\text { Satisfaction to Turnover Intention } \\
\text { Turnover Intention to Retention }\end{array}$ & -.36 & .01 & -1.96 & .15 & $1177 * *$ \\
\hline $\begin{array}{l}\text { Commitment to Turnover Intention } \\
\text { Turnover Intention to Retention }\end{array}$ & -.28 & .01 & -1.96 & .15 & \\
\hline $\begin{array}{l}\text { Role Stress to Turnover Intention } \\
\text { Turnover Intention to Retention }\end{array}$ & .17 & .01 & 1.96 & .15 & $12.58 * *$ \\
\hline
\end{tabular}

hours worked, kids at home, weekend work, and age were included as control variables in all analyses

$* \mathrm{p}<.05, * * \mathrm{p}<.01$ 
Table 6

Mediation Analyses for Morning versus Night Shift

\begin{tabular}{|c|c|c|c|c|c|}
\hline & B & se & B & se & z-score \\
\hline $\begin{array}{l}\text { Morning (1) vs. Night (2) Shift to } \\
\text { Satisfaction }\end{array}$ & .01 & .08 & & & \\
\hline Satisfaction to Turnover Intention & & & -.36 & .01 & -.07 \\
\hline $\begin{array}{l}\text { Morning (1) vs. Night (2) Shift to } \\
\text { Commitment }\end{array}$ & .13 & .09 & & & \\
\hline Commitment to Turnover Intention & & & -.27 & .01 & -1.53 \\
\hline $\begin{array}{l}\text { Morning (1) vs. Night (2) Shift to } \\
\text { Role Stress }\end{array}$ & -.04 & .08 & & & \\
\hline Stress to Turnover Intention & & & .12 & .01 & -.51 \\
\hline $\begin{array}{l}\text { Satisfaction to Turnover Intention } \\
\text { Turnover Intention to Retention }\end{array}$ & -.36 & .01 & -1.69 & .28 & $506 * *$ \\
\hline $\begin{array}{l}\text { Commitment to Turnover Intention } \\
\text { Turnover Intention to Retention }\end{array}$ & -.27 & .01 & -1.69 & .28 & 3.90 \\
\hline $\begin{array}{l}\text { Role Stress to Turnover Intention } \\
\text { Turnover Intention to Retention }\end{array}$ & .12 & .01 & -1.69 & .28 & $-5.00 * *$ \\
\hline
\end{tabular}

hours worked, kids at home, weekend work, and age were included as control variables in all analyses

${ }^{*} \mathrm{p}<.05,{ }^{* *} \mathrm{p}<.01$ 
Table 7

Mediation Analyses for Evening versus Night Shift

\begin{tabular}{lrrrrr} 
& B & se & b & se & z-score \\
\hline $\begin{array}{l}\text { Evening (1) vs. Night Shift (2) to } \\
\text { Satisfaction }\end{array}$ & -.28 & .10 & & & \\
Satisfaction to Turnover Intention & & & -.37 & .01 & $2.74^{* *}$ \\
& & & & & \\
Evening (1) vs. Night (2) Shift to & -.53 & .11 & & & \\
$\begin{array}{l}\text { Commitment } \\
\text { Commitment to Turnover Intention }\end{array}$ & & & -.29 & .02 & \\
& & & & & $4.80^{* *}$ \\
$\begin{array}{l}\text { Evening (1) vs. Night (2) Shift to } \\
\text { Role Stress }\end{array}$ & .08 & .10 & & & \\
Stress to Turnover Intention & & & .18 & .02 & \\
\end{tabular}

\begin{tabular}{|c|c|c|c|c|c|}
\hline \multirow{2}{*}{$\begin{array}{l}\text { Satisfaction to Turnover Intention } \\
\text { Turnover Intention to Retention }\end{array}$} & -.37 & .01 & & & \\
\hline & & & -2.47 & .37 & $6.51^{* *}$ \\
\hline $\begin{array}{l}\text { Commitment to Turnover Intention } \\
\text { Turnover Intention to Retention }\end{array}$ & -.29 & .02 & -2.47 & .37 & \\
\hline $\begin{array}{l}\text { Role Stress to Turmover Intention } \\
\text { Turnover Intention to Retention }\end{array}$ & .18 & .02 & -2.47 & .37 & $-5.38 * *$ \\
\hline
\end{tabular}

hours worked, kids at home, weekend work, and age were included as control variables in all analyses

$* \mathrm{p}<.05, * * \mathrm{p}<.01$ 
Table 8

Mediation Analyses for Morning versus Evening Shift

\begin{tabular}{|c|c|c|c|c|c|}
\hline & B & se & B & se & z-score \\
\hline Morning (1) vs. Evening Shift (2) to & .27 & .08 & & & \\
\hline Satisfaction to Turnover Intention & & & -.37 & .01 & $-3.35 * *$ \\
\hline $\begin{array}{l}\text { Morning (1) vs. Evening (2) Shift to } \\
\text { Commitment }\end{array}$ & .60 & .09 & & & \\
\hline Commitment to Turnover Intention & & & -.27 & .01 & $-6.54^{* *}$ \\
\hline $\begin{array}{l}\text { Morning (1) vs. Evening (2) Shift to } \\
\text { Role Stress }\end{array}$ & -.09 & .09 & & & \\
\hline Stress to Turnover Intention & & & -.27 & .01 & -.99 \\
\hline $\begin{array}{l}\text { Satisfaction to Turnover Intention } \\
\text { Turnover Intention to Retention }\end{array}$ & -.37 & .01 & -2.21 & .28 & $7.94^{* *}$ \\
\hline $\begin{array}{l}\text { Commitment to Turnover Intention } \\
\text { Turnover Intention to Retention }\end{array}$ & -.27 & .01 & -2.21 & .28 & $750^{* *}$ \\
\hline $\begin{array}{l}\text { Role Stress to Turnover Intention } \\
\text { Turnover Intention to Retention }\end{array}$ & -.27 & .01 & -2.21 & .28 & $-6.15^{* *}$ \\
\hline
\end{tabular}

hours worked, kids at home, weekend work, and age were included as control variables in all analyses

$* \mathrm{p}<.05, * * \mathrm{p}<.01$ 
Table 9

The Interaction between Mixed versus Fixed shift and Supervisor Support

\begin{tabular}{|c|c|c|c|c|}
\hline & Adjusted $\mathrm{R}^{2}$ & $\mathrm{R}^{2}$ Change & $\beta($ se $)$ & $\begin{array}{c}\text { Dependent } \\
\text { Variable }\end{array}$ \\
\hline Step 3 & .20 & .00 & & Job Satisfaction \\
\hline Kids at Home & & & $.02(.02)$ & \\
\hline Hours Worked & & & $-.004(.002)^{*}$ & \\
\hline Age & & & $.05(.01)^{* *}$ & \\
\hline Weekend Work & & & $.00(.03)$ & \\
\hline $\begin{array}{l}\text { Mixed vs. Fixed } \\
\text { Schedule (Centered) }\end{array}$ & & & $.09(.04)^{*}$ & \\
\hline $\begin{array}{l}\text { Supervisor Support } \\
\text { (Centered) } \\
\text { Mixed vs. Fixed x } \\
\text { Supervisor Support } \\
\text { Interaction } \\
\end{array}$ & & & $\begin{array}{l}.39(.01)^{* *} \\
.03(.02)\end{array}$ & \\
\hline Step 3 & .21 & .00 & & $\begin{array}{l}\text { Organizational } \\
\text { Commitment }\end{array}$ \\
\hline Kids at Home & & & $-.05(.02)^{* *}$ & \\
\hline Hours Worked & & & $-.01(.002)^{* *}$ & \\
\hline Age & & & $.03(.01)^{* *}$ & \\
\hline Weekend Work & & & $.06(.03)^{*}$ & \\
\hline $\begin{array}{l}\text { Mixed vs. Fixed } \\
\text { Schedule (Centered) }\end{array}$ & & & $.14(.04)^{* *}$ & \\
\hline $\begin{array}{l}\text { Supervisor Support } \\
\text { (Centered) }\end{array}$ & & & $.42(.01)^{* *}$ & \\
\hline $\begin{array}{l}\text { Mixed vs. Fixed x } \\
\text { Supervisor Support } \\
\text { Interaction }\end{array}$ & & & $.02(.02)$ & \\
\hline Step 3 & .08 & .00 & & Role Stress \\
\hline
\end{tabular}

Kids at Home

$.02(.02)$

Hours Worked

$.03(.002)^{* *}$

Age

$.06(.01)^{* *}$ 
Table 9 (cont)

The Interaction between Mixed versus Fixed shift and Supervisor Support

\begin{tabular}{lll}
\multicolumn{1}{c}{ Adjusted $\mathrm{R}^{2}$} & $\mathrm{R}^{2}$ Change & $\beta(\mathrm{se})$ \\
\hline Weekend Work & $.00(.03)$ \\
\hline Mixed vs. Fixed & $-.06(.04)$ \\
Schedule (Centered) & \\
Supervisor Support & $-.19(.01)^{* *}$ \\
(Centered) & $-.02(.02)$ \\
Mixed vs. Fixed $\mathrm{x}$ & \\
Supervisor Support & \\
Interaction & \\
\hline$* \mathrm{p}<.05, * * \mathrm{p}<.01$ &
\end{tabular}


Table 10

The Interaction between Individual Shifts and Supervisor Support on Organizational Commitment

\begin{tabular}{ccccc} 
& Adjusted $\mathrm{R}^{2}$ & $\mathrm{R}^{2}$ Change & $\beta(\mathrm{se})$ & Shift Variable \\
\hline Step 3 & .20 & .00 & $\begin{array}{c}\text { Morning versus } \\
\text { Night Shift }\end{array}$
\end{tabular}

Kids at Home

Hours Worked

$-.01(.01)^{*}$

Age

$.10(.02)^{* *}$

Morning vs. Night Shift

$.18(.08)^{*}$

(Centered)

Supervisor Support

$.39(.02)^{* *}$

(Centered)

Morning vs. Night $\mathrm{x}$

Supervisor Support

$.02(.05)$

Interaction

Step 3

.24

.00

Evening vs.

Kids at Home

$.08^{*}$

Night Shift

Hours Worked

$.00(.01)$

Age

$.05(.02)$

Evening vs. Night Shift

(Centered)

$-.41(.10)^{* *}$

Supervisor Support

$.42(.03)^{* *}$

(Centered)

Evening vs. Night $\mathrm{x}$

$.00(.05)$

Supervisor Support

Interaction

Step 3

.22

.00

Morning vs.

Kids at Home

$-.07(.03)^{*}$

Evening Work

Hours Worked

$-.01(.00)^{*}$

Age

$.08(.02)^{* *}$ 
Table 10 (cont)

The Interaction between Individual Shifts and Supervisor Support on

Organizational Commitment

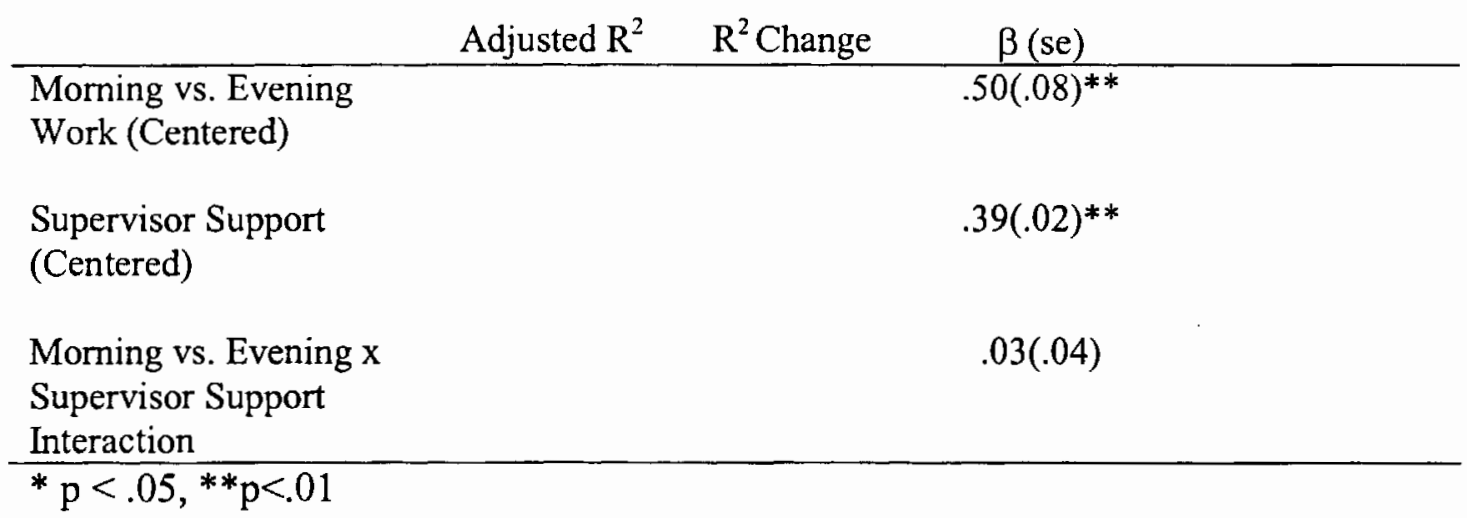


Table 11

The Interaction between Individual Shifts and Supervisor Support on Job Satisfaction

\begin{tabular}{ccc} 
& Adjusted $\mathrm{R}^{2}$ & $\mathrm{R}^{2}$ Change \\
\hline Step 3 & .17 & .00
\end{tabular}

Kids at Home

$\beta(\mathrm{se})$

Hours Worked

Age

$.11(.02)^{* *}$

Morning vs. Night Shift

$.04(.08)$

(Centered)

Shift Variable

Supervisor Support

(Centered)

Morning vs. Night Shift

$.03(.04)$

x Supervisor Support

Interaction

Step 3

.47

.00

Evening vs.

Morning vs.

Night Shift

Kids at Home

$$
.06(.04)
$$

Night Shift

Hours Worked

Age

$.07(.02)^{* *}$

Evening vs. Night Shift

(Centered)

$.38(.03)^{* *}$

Supervisor Support

(Centered)

Mixed vs. Fixed $x$

Supervisor Support

Interaction

Step 3

.19

.00

Morning vs.

Kids at Home

$-.05(.03)$

Evening Shift

Hours Worked

$-.01(.00)$

Age

$.09(.02)^{* *}$ 
Table 11 (cont)

The Interaction between Individual Shifts and Supervisor Support on Job Satisfaction

\begin{tabular}{lccc} 
& Adjusted $\mathrm{R}^{2}$ & $\mathrm{R}^{2}$ Change & $\beta(\mathrm{se})$ \\
\hline $\begin{array}{l}\text { Morning vs. Evening } \\
\text { Shift (Centered) }\end{array}$ & & $.17(.08)^{*}$
\end{tabular}

Supervisor Support

(Centered)

Morning vs. Evening $\mathrm{x}$

$.08(.04)$

Supervisor Support

Interaction

${ }^{*} \mathrm{p}<.05,{ }^{* *} \mathrm{p}<.01$ 
Table 12

The Interaction between Individual Shifts and Supervisor Support on Role Stress

\begin{tabular}{lcr} 
& Adjusted $\mathrm{R}^{2}$ & $\mathrm{R}^{2} \mathrm{Ch}$ \\
\hline Step 3 & .06 & .00
\end{tabular}

Kids at Home $\beta$ (se) Shift Variable

Hours Worked $.07(.03)^{*}$

Age $.03(.01)^{* *}$ $.05(.02)^{*}$

Morning vs. Night Shift $-.05(.08)$ (Centered)

Supervisor Support (Centered)

Morning vs. Evening $x$

Supervisor Support

Interaction

\begin{tabular}{lll}
\hline Step 3 & .10 & .00
\end{tabular}

Kids at Home $.00(.04)$

Hours Worked

$$
.02(.01)^{* *}
$$

Age

$$
.05(.02)^{*}
$$

Evening vs. Night Shift

(Centered)

Evening vs.

Night Shift

Night Shift

Supervisor Support

(Centered)

Evening vs. Night $x$

Supervisor Support

$.02(.05)$ Interaction

Step 3

Kids at Home

$$
.06(.03)
$$

Evening Shift

Hours Worked 
Age

$.05(.02)^{*}$

Table 12 (cont)

The Interaction between Individual Shifts and Supervisor Support on Role Stress

Adjusted $\mathrm{R}^{2} \quad \mathrm{R}^{2}$ Change

$\beta(\mathrm{se})$

Morning vs. Evening

$-.02(.09)$

Shift (Centered)

Supervisor Support

$-.16(.02)^{* *}$

(Centered)

Morning vs. Evening $\mathrm{x}$

$-.10(.05)^{*}$

Supervisor Support

Interaction

${ }^{*} \mathrm{p}<.05,{ }^{* *} \mathrm{p}<.01$ 
The effects of non-standard shift work 98

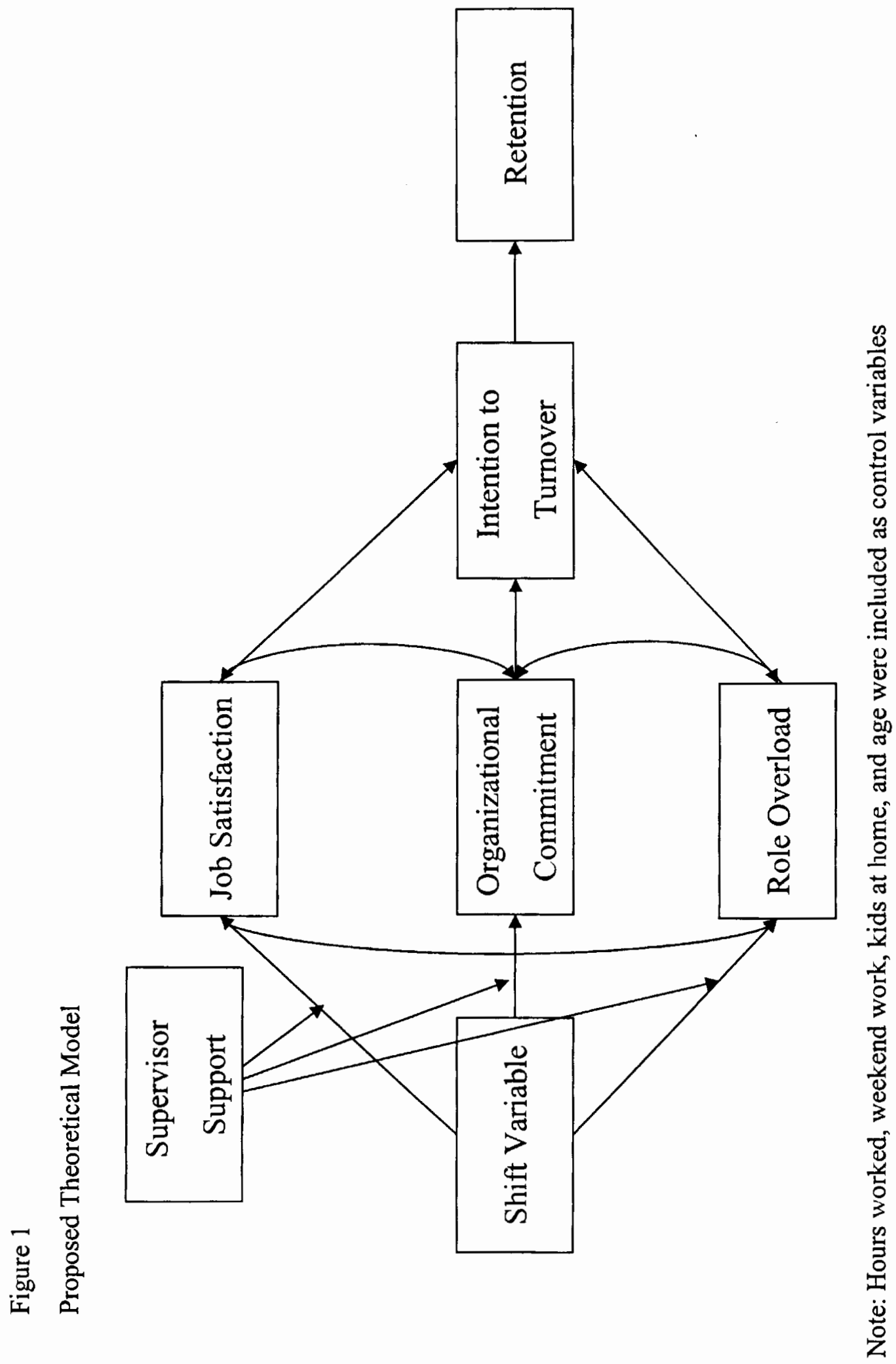


The effects of non-standard shift work

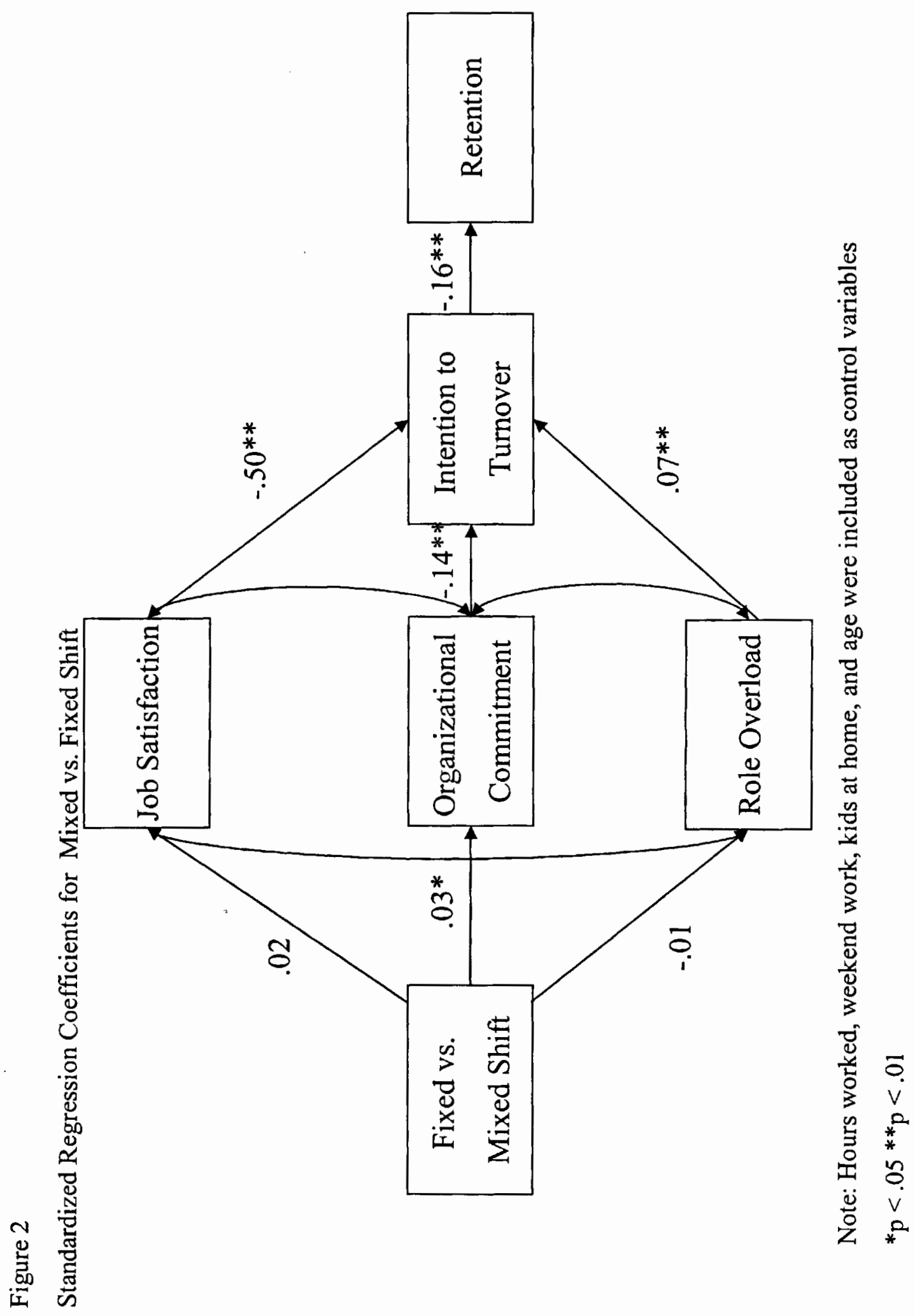


The effects of non-standard shift work 100

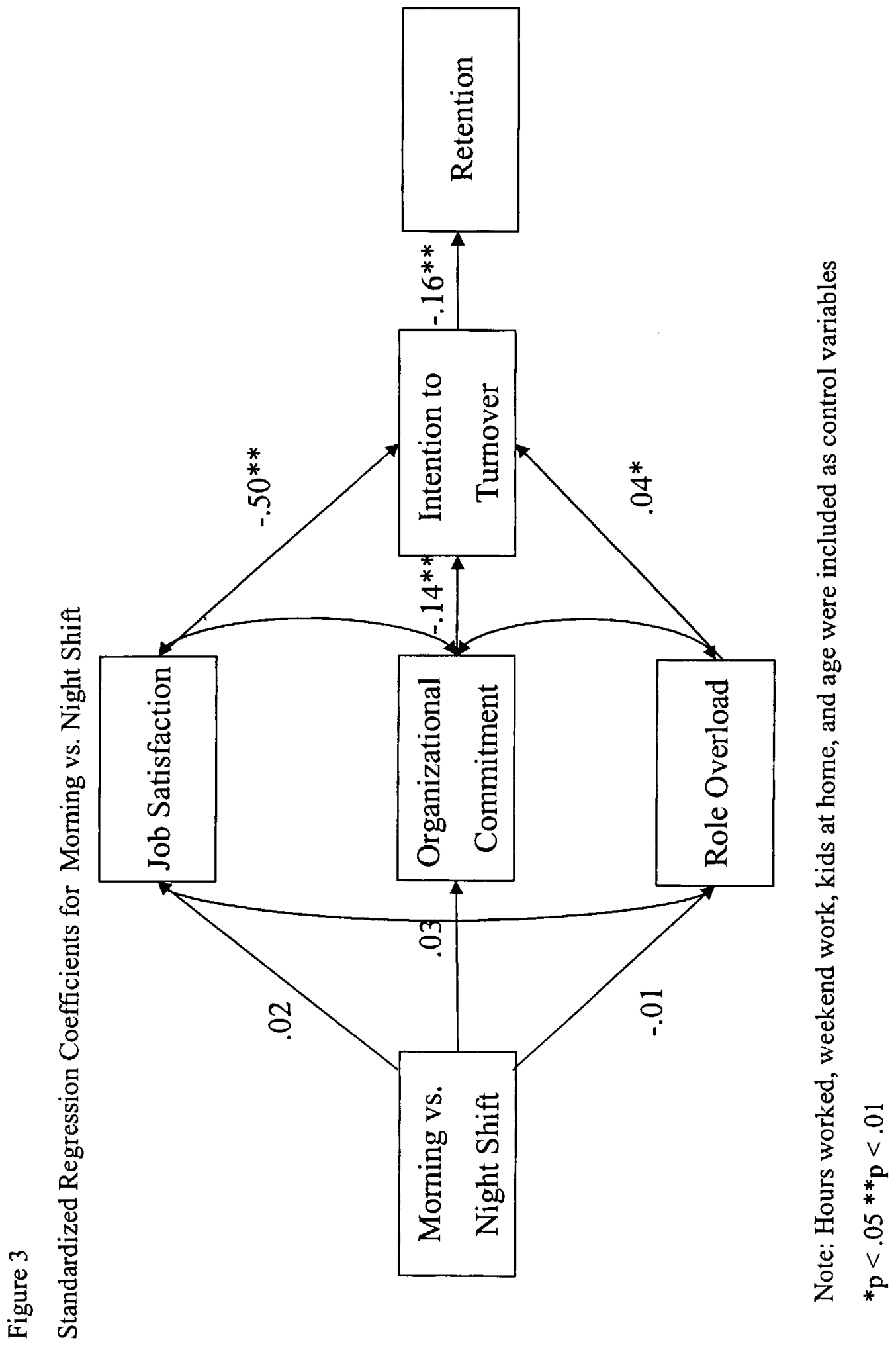




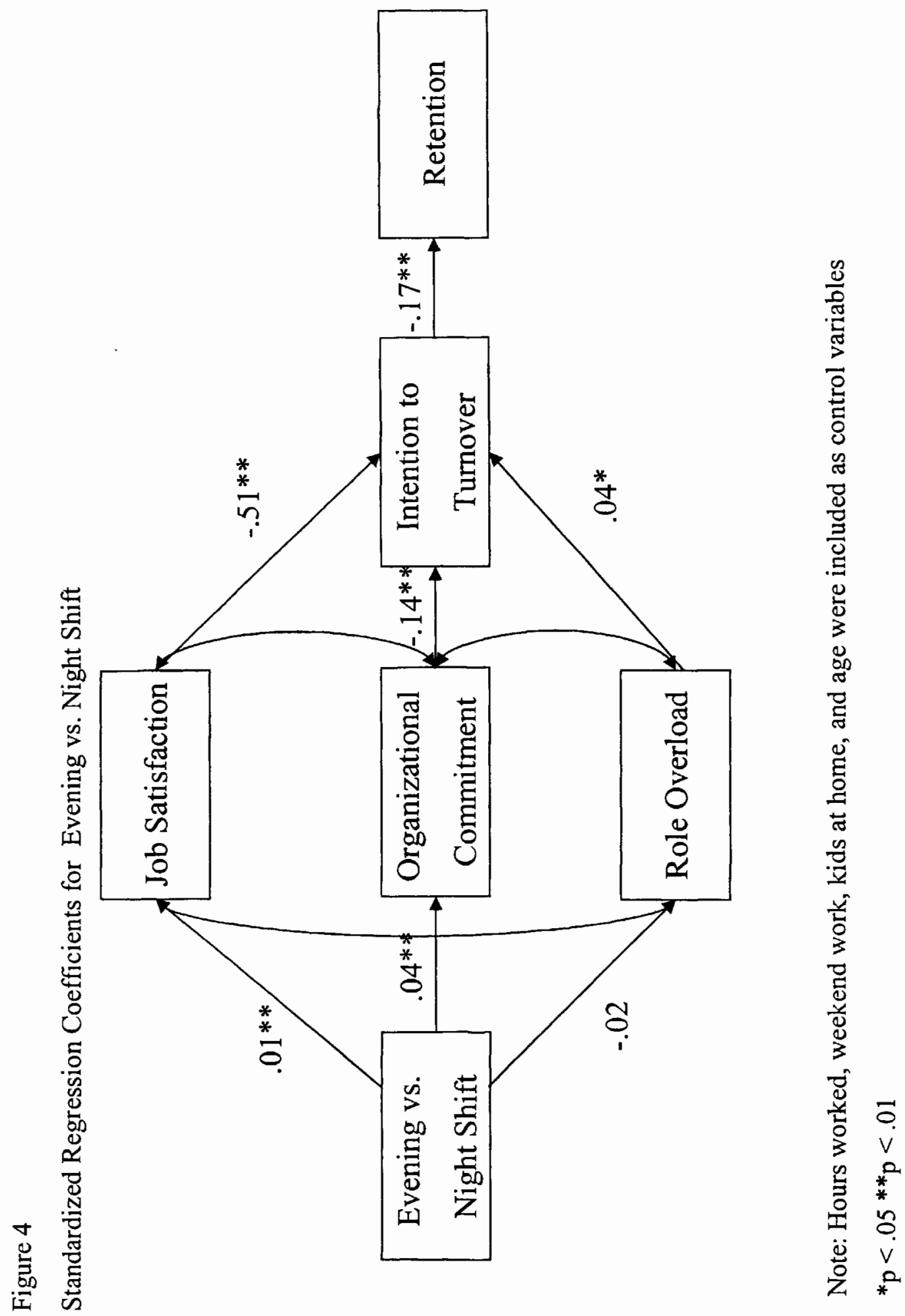


The effects of non-standard shift work 102

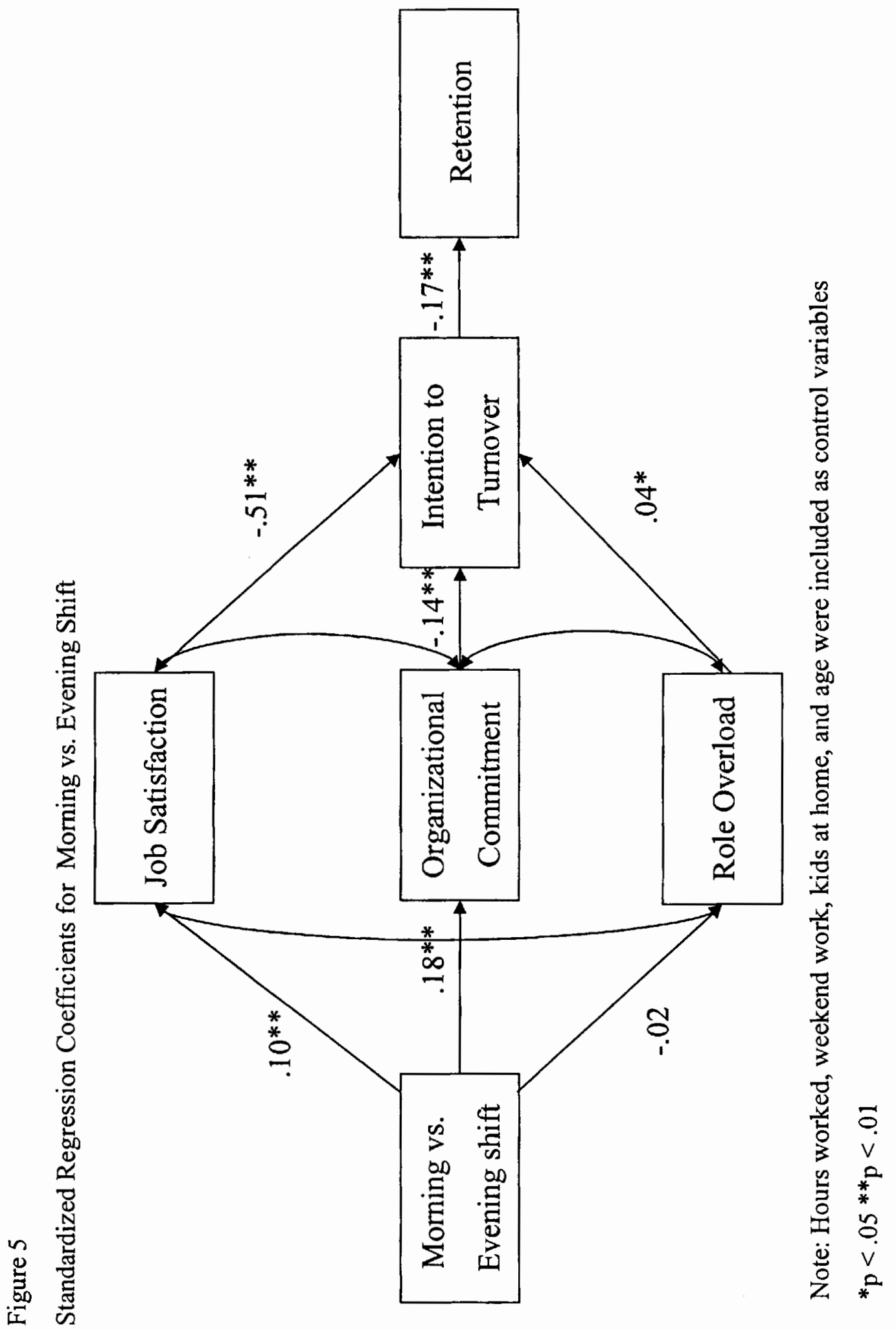


Figure 6

Interaction between Morning versus Evening Shift and Supervisor Support

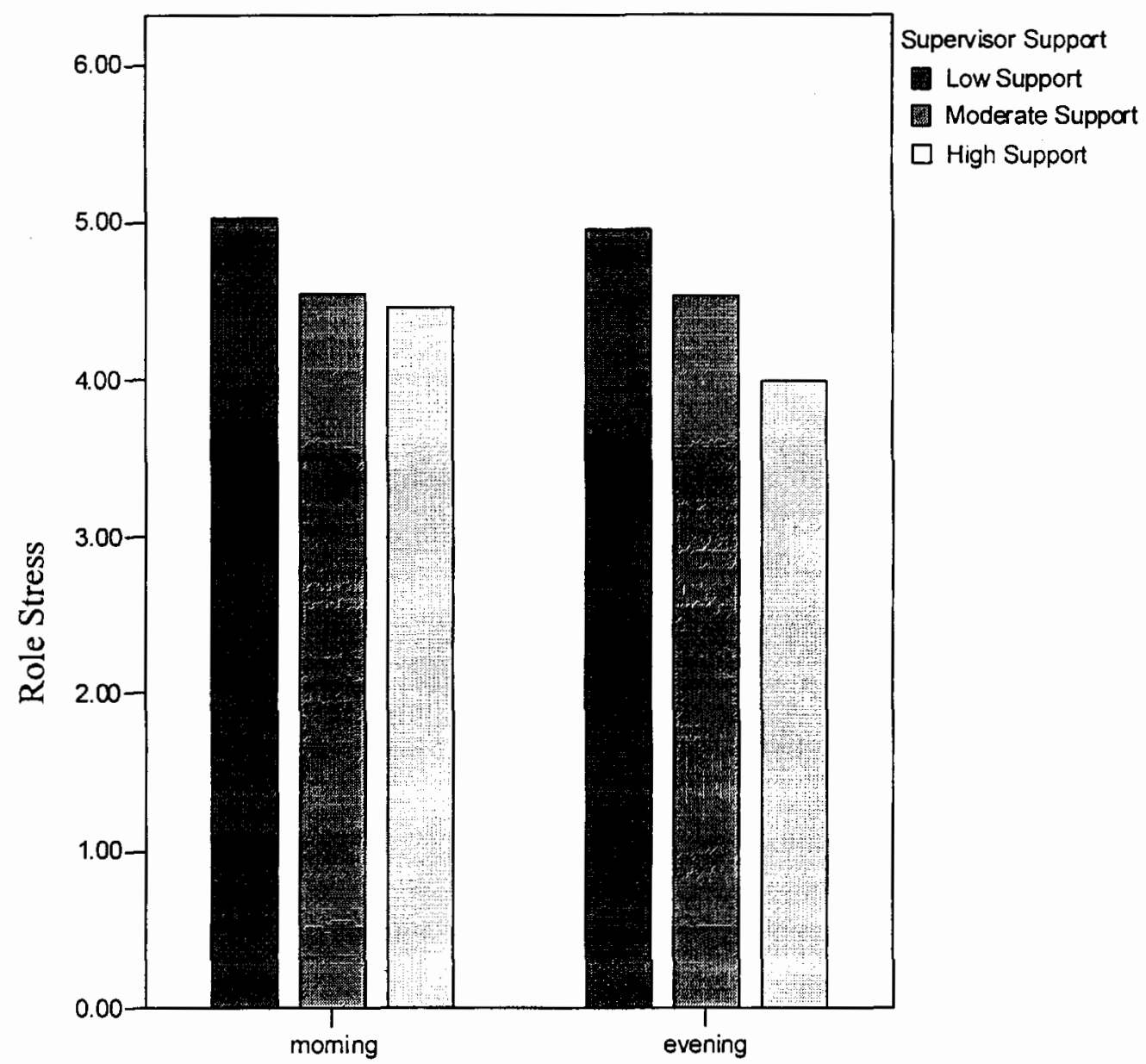

Morning vs. Evening Shift 


\section{References}

Akerstedt, T. (1995). Work hours, sleepiness and the underlying mechanisms. Journal of Sleep Research, 4, 15-22.

Arbuckle, J. L. (1999). AMOS 4.0. Chicago: Smallwaters.

Baba, V. V., \& Jamal, M. (1992). How much do we really know about moonlighters? Public Personnel Management, 21, 65-73.

Babin, B. J., \& Boles, J. S. (1996). The effects of percieved co-worker involvement and supervisor support on service provider role stress, performance, and job satisfaction. Journal of Retailing, 72, 57-75.

Barton, J. (1994). Choosing to work at Night - a moderating influence on individual tolerance to shift work. Journal of Applied Psychology, 79, 449-454.

Beers, T. M. (2000). Flexible schedules and shift work: replacing 9-5 workday? Monthly Labor Review, June, 33-40.

Bentler, P. M. (1990). Comparative fix indexes in structural models. Psychological Bulletin, 107, 238-246.

Blau, G. J., \& Lunz, M. (1999). Testing the impact of shift schedules on organizational variables. Journal of Organizational Behavior, 20,933-942.

Bliese, P., \& Castro, C. A. (2000). Role clarity, work overload, and organizational support; multilevel evidence of the importance of support. Work \& Stress, 14, 6573. 
Bohle, P., \& Tilley, A. J. (1998). Early experiences of shiftwork: Influences on attitudes. Journal of Occupational and Organizational Psychology, 71, 61-79.

Bourdouxhe, M. A., Queinnec, Y., Granger, D., Baril, R. H., Guertin, S. C., Massicotte, P. R., et al. (1999). Aging and shiftwork: The effects of 20 years of rotating 12-hour shifts among petroleum refinery operators. Experimental Aging Research, 25, 323-329.

Brief, A. P. (1998). Attitudes in and around organizations: SAGE.

Browne, M. W., \& Cudeck, R. (1993). Alternative ways of assessing model fit. In K.

A. Bollen \& J. S. Long (Eds.), Testing structural equation models. Thousand Oaks, CA: Sage.

Cammann, C., Fichman, M., Jenkins, G. D., \& Klesh, J. R. (1983). Assessing the attitudes and perceptions of organizational members. In S. E. Seashore, E. E. Lawler, P. H. Mirvis \& C. Cammann (Eds.), Assessing Organizational Change: A Guide to Methods, Measures, and Practices (pp. 71-138). New York: Wiley. Circadian Technologies, I. (2003). Overtime in U.S. Extended Hour Operations Continues to Rise. Retrieved Feb. 2, 2003, from http://www.circadian.com/media/2003 press overtime.htm

Cohen, A. (1993). Organizational commitment and turnover: A meta-analysis. Academy of Management Journal, 36, 1140-1157.

Cohen, A., \& Hudecek, N. (1993). Organizational commitment-turnover relationship across occupational groups: A meta-analysis. Group \& Organization Management, $18,188-213$. 
Costa, G. (1996). The impact of shift and night work on health. Applied Ergonomics, 27, 9-16.

Cotton, J., \& Tuttle, J. M. (1986). Employee turnover: A meta-analysis and review with implications for research. Academy of Management Review, 11, 55-70.

Dollard, M. F., Winefield, H. R., Winefield, A. H., \& de Jonge, J. (2000).

Psychosocial job strain and productivity in human service workers: A test of the demand-control-support model. Journal of Occupational \& Organizational Psychology, 73, 501-510.

Dunham, R. B. (1977). Shift work: A review and theoretical analysis. Academy of Management Review, 2, 624-634.

Eby, L. T., Freeman, D. M., Rush, M. C., \& Lance, C. E. (1999). Motivational bases for affective organizational commitment: A partial test of an integrative theoretical model. Journal of Occupational \& Organizational Psychology, 72, 463-483.

Eisenberger, R., Stinglhamber, F., Vandenberghe, C., Sucharski, I. L., \& Rhoades, L. (2002). Perceived supervisor support: Contributions to perceived organizational support and employee retention. Journal of Applied Psychology, 87, 565-573.

Folkard, S., Akerstedt, T., Macdonald, I., Tucker, P., \& Spencer, M. B. (2000).

Beyond the three-process model of alertness: Estimating phase, time on shift, and successive night effects. Journal of Biological Rhythms, 14, 577-587.

Furnham, A., \& Hughes, K. (1999). Individual difference correlates of nightwork and shift-work rotation. Personality and Individual Differences, 26, 941-959. 
Gold, D. R., Rogacz, S., Bock, N., Tosteson, T. D., Baum, T. M., Speizer, F. E., et al. (1992). Rotating Shift Work, Sleep, and Accidents Related to Sleepiness in Hospital Nurses. American Journal of Public Health, 82, 1011-1014.

Good, L. K., Sisler, G. F., \& Gentry, J. W. (1988). Antecedents of turnover intentions among retail management personnel. Journal of Retailing, 64, 295-314.

Goodrich, S., \& Weaver, K. A. (1998). Differences in depressive symptoms between traditional workers and shiftworkers'. Psychological Reports, 83, 571-576.

Griffeth, R. W., \& Hom, P. W. (2001). Retaining Valued Employees. Thousand Oaks, CA: Sage Publications.

Griffeth, R. W., Hom, P. W., \& Gaertner, S. (2000). A meta-analysis of antecedents and correlates of employee turnover: Update, moderator tests, and research implications for the next millennium. Journal of Management, 26, 463-488.

Griffin, M. A., Patterson, M. G., \& West, M. A. (2001). Job satisfaction and teamwork: The role of supervisor support. Journal of Organizational Behavior, $22,537-550$.

Healy, D., Minors, D. S., \& Waterhouse, J. M. (1993). Shiftwork, helplessness, and depression. Journal of Affective Disorders, 29, 17-25.

Hemingway, M. A., \& Smith, C. A. (1999). Organizational climate and occupational stressors as predictors of withdrawal behaviors and injuries in nurses. Journal of Occupational \& Organizational Psychology, 72, 285-299. 
Hildebrandt, G., \& Stratmann, I. (1979). Circadian system response to night work in relation to the individual circadian phase position. International Archives of Occupational and Environmental Health, 43, 73-83.

Holtom, B. C., Lee, T. W., \& Tidd, S. T. (2002). The relationship between work status congruence and work-related attitudes and behaviors. journal of Applied Psychology, 87, 903-915.

Hom, P. W., \& Griffeth, R. W. (1991). Structural equations modeling test of turnover theory: Cross-sectional and longitudinal analyses. Journal of Applied Psychology, $76,350-366$.

Hom, P. W., \& Griffeth, R. W. (1995), Employee Turnover. Cincinnati, OH: SouthWestern College Publishing.

Homans, G. C. (1958). Social behavior as exchange. The American Journal of Sociology, 63, 597-606.

Howell, D. C. (2002). Statistical Methods for Psychology (5th Edition ed.). Australia: Duxbury.

Hu, L. T., \& Bentler, P. M. (1999). Cutoff criteria for fit indexes in covariance structure analysis: Conventional criteria versus new alternatives. Structural Equation Modeling: A multidisciplinary journal, 6, 1-55.

Jamal, M. (1981). Shift work related to job attitudes, social participation and withdrawal behavior: A study of nurses and industrial workers. Personnel Psychology, 34, 535-547. 
Jamal, M., \& Baba, V. V. (1992). Shiftwork and department-type related job stress, work attitudes and behavioral intentions: A study of nurses. Journal of Organizational Behavior, 13, 449-464.

Jamal, M., \& Baba, V. V. (1997). Shiftwork, burnout, and well-being: A study of Canadian nurses. International Journal of Stress Management, 4, 197-204. Johnson, J. V., \& Hall, E. M. (1988). Job strain, work place social support, and cardiovascular disease: A cross-sectional study of a random sample of the Swedish working population. American Journal of Public Health, 78, 1336-1342.

Judge, T. A., Parker, S., Colbert, A. E., Heller, D., \& Ilies, R. (2001). Job satisfaction:

A cross-cultural review. In N. Anderson, D. S. Ones, H. K. Sinangil \& C. Viswesvaran (Eds.), Handbook of Industrial, Work, and Organizational Psychology (Vol. 2, pp. 25-52). London: Sage.

Kahn, R. L., Wolfe, D. M., Quinny, R. P., Snoek, J. D., \& Rosenthal, R. A. (1964). Organizational stress: Studies in role conflict and ambiguity. New York: John Wiley \& Sons, Inc.

Kandolin, I. (1993). Burnout of Female and Male Nurses in Shiftwork. Ergonomics, $36,141-147$.

Karasek, R., \& Theorell, T. (1990). Health Work: Stress, productivity and the reconstruction of working life. New York: Basic Books.

Khaleque, A. (1999). Sleep deficiency and quality of life on shift workers. Social Indicators Research, 46, 181-189. 
Kidd, J. M., \& Smewing, C. (2001). The role of the supervisor in career and organizational commitment. European Journal of Work and Organizational Psychology, 10, 25-40.

Kivimaki, M., Kuisma, P., Virtanen, M., \& Elovainio, M. (2001). Does shift work lead to poorer health habits? A comparison between women who had always done shift work with those who had never done shift work. Work and Stress, 15, 3-13.

Knauth, P. (1996). Designing better shift systems. Applied Ergonomics, 27, 39-44.

Krausz, M., Sagie, A., \& Bidermann, Y. (2000). Actual and preferred work schedules and scheduling control as determinants of job-related attitudes. Journal of Vocational Behavior, 56, 1-11.

Lambert, E. G., Hogan, N. L., \& Barton, S. M. (2001). The impact of job satisfaction on turnover intent: A test of a structural measurement model using a national sample of workers. Social Science Journal, 38, 233-250.

Lee, T. W., \& Johnson, D. R. (1991). The effects of work schedule and employment status on the organizational commitment and job satisfaction of full versus part time employees. Journal of Vocational Behavior, 38, 208-224.

Lee, T. W., \& Mitchell, T. R. (1994). An Alternative Approach - the Unfolding Model of Voluntary Employee Turnover. Academy of Management Review, 19, 51-89. Locke, E. A. (1976). The nature and causes of job satisfaction. In M. D. Dunnette (Ed.), Handbook of Industrial and Organizational Psychology. Chicago: Rand McNally. 
MacKinnon, D. P., \& Dwyer, J. H. (1993). Estimating mediated effects in prevention studies. Evaluation Review, 17, 144-158.

MacKinnon, D. P., Lockwood, C. M., Hoffman, J. M., West, S. G., \& Sheets, V. (2002). A comparison of methods to test mediation and other intervening variable effects. Psychological Methods, 7, 83-104.

March, J. G., \& Simon, H. A. (1958). Organizations. New York: Wiley.

Martin, J. E., \& Peterson, M. M. (1987). Two-tier wage structures: Implications for equity theory. Academy of Management Journal, 30, 297-315.

Martin, J. E., \& Sherman, M. P. (forthcoming). Voting in an Officer Election: Testing a Model in a Multi-

Site Local. Journal of Labor Research.

Mathieu, J. E., \& Zajac, D. M. (1990). A review and meta-analysis of the antecedents, correlates, and consequences of organizational commitment. Psychological Bulletin, 108, 171-194.

McDonald, R. P., \& Ho, M. R. (2002). Principles and practice in reporting structural equation analysis. Psychological Methods, 7, 64-82.

McIntyre, J. (1988). Women in part time management in the retail sector: The employees' viewpoint. Personnel Review, 29, 637-653.

Meyer, J. P., \& Allen, N. J. (1984). Testing the "side-bet theory" of organizational commitment: Some methodological considerations. Journal of Applied Psychology, 69, 372-378. 
Meyer, J. P., \& Allen, N. J. (1987). A longitudinal analysis of the early development and consequences of organizational commitment. Canadian Journal of Behavioural Science, 19, 199-215.

Meyer, J. P., \& Allen, N. J. (1991). A three-component conceptualization of organizational commitment. Human Resource Management Review, 1, 61-89.

Meyer, J. P., Allen, N. J., \& Smith, C. A. (1993). Commitment to organizations and occupations: Extension and test of a three-component conceptualization. Journal of Applied Psychology, 78, 538-551.

Mobley, W. H. (1977). Intermediate linkages in the relationship between job satisfaction and voluntary turnover? Journal of Applied Psychology, 62, 237-240. Mobley, W. H., Homer, S. O., \& Hollingsworth, A. T. (1978). An evaluation of precursors of hospital employee turnover. Journal of Applied Psychology, 63, 408414.

Mowday, R. T., Porter, L. W., \& Steers, R. M. (1982). Employee-organization linkages: The psychology of commitment, absenteeism, and turnover. New York: Academic Press.

Muchinsky, P. M., \& Morrow, P. C. (1980). A multidisciplinary model of voluntary employee turnover. Journal of Vocational Behavior, 17, 263-290.

Olsson, K., Kandolin, I., \& Kauppinen-Toropainen, K. (1990). Stress and coping strategies of three-shift workers. Le Travail Humain, 53, 175-188. 
Parkes, K. R. (1999). Shiftwork, job type, and the work environment as joint predictors of health-related outcomes. Journal of Occupational Health Psychology, 4, 256-268.

Parkes, K. R. (2002). Age, smoking, and negative affectivity as predictors of sleep patterns among shiftworkers in two environments. Journal of Occupational Health Psychology, 7, 156-173.

Parkes, K. R. (2003). Shiftwork, and environment as interactive predictors of work perception. Journal of Occupational Health Psychology, 8, 266-281.

Pattanayak, B. (2002). Effects of shiftwork and hierarchical position in the organization on psychological correlates: A study on an integrated steel plant. Organization Development Journal, 20, 71-82.

Peters, L., Jackofsky, E., \& Salter, J. (1981). Predicting turnover: A comparison of part-time and full-time employees. Journal of Occupational Behavior, 2, 89-98.

Pierce, J. L., \& Dunham, R. D. (1992). The 12-hour work day: A 48-hour, eight-day week. Academy of Management Journal, 35, 1086-1098.

Preacher, K. J. (2003). An interactive calculation tool for mediation tests. Retrieved June 5, 2004, from http://www.unc.edu/ preacher/sobel/sobel.htm

Presser, H. B. (1994). Employment Schedules among Dual-Earner Spouses and the Division of Household Labor by Gender. American Sociological Review, 59, 348364.

Presser, H. B. (1995). Job, family, and gender: Determinants of nonstandard work schedules among employed Americans in 1991. Demography, 32, 577-598. 
Presser, H. B. (2000). Nonstandard work schedules and marital instability. Journal of Marriage and the Family, 62, 93-110.

Presser, H. B. (2003). Working in a 24/7 Economy. New York: Russell Sage Foundation.

Prizmic, Z., \& Kaliterna, L. (1995). Relationship between positive and negative affect and measures of tolerance to shiftwork. Psychologia Croatica, 1, 155-164.

Rhoades, L., \& Eisenberger, R. (2002). Perceived organizational support: A review of the literature. Journal of Applied Psychology, 87, 698-714.

Rhoades, L., Eisenberger, R., \& Armeli, S. (2001). Affective commitment to the organization: The contribution of perceived organizational support. Journal of Applied Psychology, 86, 825-836.

Salminen. (1998). Increased risk of work-related violence during weekend nights. Perceptual and Motor Skills, 87, 984-986.

Schmieder, R. A., \& Smith, C. A. (1996). Moderating effects of social support in shiftworking and non-shiftworking nurses. Work and Stress, 10, 128-140.

Shaw, J. B., \& Weekley, J. A. (1985). The effects of objective work-load variations of psychological strain and post-work-load performance. Journal of Management, 11, 87-98.

Shields, M. (2002). Shift work and health. Health Reports, 13, 11-33.

Smith, C. S., Folkard, S., \& Fuller, J. A. (2003). Shift work and working hours. In J. C. Quick \& L. E. Tetrick (Eds.), Handbook of Occupational Health Psychology. Washington DC: APA. 
Smith, C. S., Folkard, S., Schmieder, R. A., Parra, L. F., Spelten, E., Almiral, H., et al. (2002). Investigation of morming-evening orientation in six countries using the preferences scale. Personality and Individual Differences, 32, 949-968.

Smith, C. S., Robie, C., Folkard, S., Barton, J., Macdonald, I., Smith, L., et al. (1999). A process model of shiftwork and health. Journal of Occupational Health Psychology, 4, 207-218.

Smith, L., Folkard, S., \& Poole, C. J. M. (1994). Increased injuries on night shift. Lancet, 344, 1137-1139.

Snyder, R. A. (1995). One man's time warp is another (wo)man's treasure: The importance of individual and situational differences in shiftwork tolerance and satisfaction. Human Resources Development Quarterly, 6, 397-407.

Sobel, M. E. (1982). Asymptotic confidence intervals for indirect effects in structural equation models. In S. Leinhardt (Ed.), Sociological Methodology (pp. 46-64). Beverly Hills: Sage.

Spector, P. E. (1997). Job Satisfaction: Application, Assessment, Causes, and Consequences. Thousand Oaks: Sage Publications.

Staines, G. L., \& Pleck, J. H. (1984). Nonstandard work schedules and family life. Journal of Applied Psychology, 69, 515-523.

Taylor, E., Briner, R. B., \& Folkard, S. (1997). Models of shiftwork and health: An examination of the influence of stress on shiftwork theory. Human Factors, 39, 6782. 
Tett, R. P., \& Meyer, J. P. (1993). Job satisfaction, organizational commitment, turnover intention, and turnover: Path analyses based on meta-analytic findings. Personnel Psychology, 46, 259-293.

Tucker, P., Smith, L., Macdonald, I., \& Folkard, S. (1998). The impact of early and late shift changeovers on sleep, health, and well-being in 8- and 12-hour shift systems. Journal of Occupational Health Psychology, 3, 265-275.

Wayne, S. J., Shore, L. M., Bommer, W. H., \& Tetrick, L. E. (2002). The role of fair treatment and rewards in perceptions of organizational support and leader-member exchange. Journal of Applied Psychology, 87, 590-598.

Williamson, A. M., \& Feyer, A.-M. (1995). Causes of accidents and the time of day. Work \& Stress, 9, 158-164.

Wright, T. A., \& Bonett, D. G. (2002). The moderating effects of employee tenure on the relation between organizational commitment and job performance: A metaanalysis. Journal of Applied Psychology, 87, 1183-1190.

Wright, T. A., \& Cropanzano, R. (1998). Emotional exhaustion as a predictor of job performance and voluntary turnover. Journal of Applied Psychology, 83, 486-493.

Zedeck, S., Jackson, S. E., \& Marca, E. S. (1983). Shift work schedules and their relationship to health, adaptation, satisfaction, and turnover intention. Academy of Management Journal, 26, 297-310. 


\section{Appendix A}

\section{Questionnaire Scale Items}

\section{Organizational Commitment}

I talk up (my company) to my friends as a great employer to work for.

I find that my values and (my company's) values are very similar.

I am proud to tell others that I am part of (my company).

\section{Job Satisfaction}

All in all, I am satisfied with my job.

In general, I like working here.

In general, I don't like my job (R).

\section{Role Stress}

I find it hard to relax on my job.

I always feel under time pressure at work.

I find it hard to keep up with my work load.

\section{Turnover Intention}

I often think about quitting.

I will probably look for a new job in the next year.

I have too much at stake to change jobs next year (R)

How likely is it that you will actively look for a new job in the next year?*

Supervisor Support

My immediate supervisor is always fair with me.

My immediate supervisor stands up for me with "higher ups." 
My immediate supervisor encourages me to participate in important decisions.

*Answered on 1-5 scale (not at all likely, slightly likely, moderately likely, very likely, extremely likely) 
Appendix B

Summary of Hypotheses

\section{Hypotheses to confirm prior research}

Hypothesis 1: Individuals with stronger turnover intentions will be more likely to actually leave the organization.

Hypothesis 2a: Intention to turnover will mediate the positive relationship between organizational commitment and retention.

Hypothesis $2 b$ : Intention to turnover will mediate the positive relationship between job satisfaction and turnover.

Hypothesis 2c: Intention to turnover will mediate the negative relationship between role stress and turnover.

Hypothesis 5: Employees who report lower levels of affective commitment will report stronger turnover intentions that those who report high levels of commitment.

Hypothesis 10: Employees who report lower levels of job satisfaction will have stronger turnover intentions than those who report high levels of job satisfaction.

Hypothesis 15: Employees who report higher levels of role stress will report stronger turnover intentions than those who report lower levels of role stress. 


\section{Hypotheses associated with model testing}

Hypothesis 3: Employees working a mixed shift schedule will report less affective organizational commitment than employees working a fixed shift schedule.

Hypothesis 4a: Employees working night shifts will report less affective organizational commitment to their organization than employees working morning shifts.

Hypothesis 4b: Employees working night shifts will report less affective organizational commitment than employees working evening shifts.

Hypothesis 4c: Employees working morning shifts will differ in their levels of affective organizational commitment from employees working evening shifts. Hypothesis 8: Employees working a mixed shift schedules will report less job satisfaction than employees working a fixed shift schedule.

Hypothesis 9a: Employees working night shifts will report less job satisfaction than employees working morning shifts.

Hypothesis $9 b$ : Employees working night shifts will report less job satisfaction than employees working evening shifts.

Hypothesis $9 c$ : Employees working morning shifts will differ in their levels of job satisfaction from employees working evening shifts.

Hypothesis 13: Employees working a mixed shift schedule will report more role stress than employees working a fixed shift schedule. 
Hypothesis 14a: Employees working night shifts will report more role stress than employees working morning shifts.

Hypothesis 14b: Employees working night shifts will report more role stress than employees working evening shifts.

Hypothesis 14c: Employees working morning shifts will differ in their levels of role stress from employees working evening shifts.

\section{Hypotheses to test mediation of commitment, satisfaction, and role stress}

Hypotheses 6: Organizational commitment will mediate the relationship between mixed versus fixed shift work and intention to turnover. Hypothesis 7a: Organizational commitment will mediate the relationship between morning versus night work and intention to turnover. Hypothesis $7 b$ : Organizational commitment will mediate the relationship between evening work versus night work and intention to turnover. Hypothesis 7c: Organizational commitment will mediate the relationship between morning versus evening work and intention to turnover. Hypothesis 11: Job satisfaction will mediate the relationship between mixed versus fixed shift work and intention to turnover.

Hypothesis 12a: Job satisfaction will mediate the relationship between morning versus night work and intention to turnover.

Hypothesis $12 b$ : Job satisfaction will mediate the relationship between evening versus night work and intention to turnover. 
Hypothesis 12c: Job satisfaction will mediate the relationship between morning versus evening work and intention to turnover.

Hypothesis 16: Role stress will mediate the relationship between mixed versus fixed shift work and intention to turnover.

Hypothesis 17a: Role stress will mediate the relationship between morning versus night work and intention to turnover.

Hypothesis 17b: Role stress will mediate the relationship between evening versus night work and intention to turnover.

Hypothesis $17 c$ : Role stress will mediate the relationship between morning versus evening shift and intention to turnover.

\section{Hypotheses to test the moderation of supervisor support}

Hypothesis 18: The relationship between fixed versus mixed shift schedules and affective organizational commitment will be stronger for individuals with low levels of perceived supervisor support.

Hypothesis 19a: The relationship between morning versus night shift work and affective organizational commitment will be stronger for individuals with low levels of perceived supervisor support.

Hypothesis 19b: The relationship between evening versus night shift work and affective organizational commitment will be stronger for individuals with low levels of perceived supervisor support. 
Hypothesis 19c: The relationship between moming versus evening shift work and affective organizational commitment will be stronger for individuals with low levels of perceived supervisor support.

Hypothesis 20: The negative relationship between fixed versus mixed shift schedules and job satisfaction will be stronger for individuals with low levels of perceived supervisor support.

Hypothesis 21a: The relationship between morning versus night shift work and job satisfaction will be stronger for individuals with low levels of perceived supervisor support.

Hypothesis $21 \mathrm{~b}$ : The relationship between evening versus night shift work and job satisfaction will be stronger for individuals with low levels of perceived supervisor support.

Hypothesis 21c: The relationship between morning versus evening shift work and job satisfaction will be stronger for individuals with low levels of perceived supervisor support.

Hypothesis 22: The positive relationship between fixed versus mixed shift schedules and role stress will be stronger for individuals with low levels of perceived supervisor support.

Hypothesis 23a: The relationship between morning versus night shift work and role stress will be stronger for individuals with low levels of perceived supervisor support. 
Hypothesis 23b: The relationship between evening versus night shift work and role stress will be stronger for individuals with low levels of perceived supervisor support.

Hypothesis 23a: The relationship between morning versus evening shift work and role stress will be stronger for individuals with low levels of perceived supervisor support. 